\title{
Liogenys Guerin-Méneville, 1831 (Coleoptera: Scarabaeidae: Melolonthinae: Diplotaxini) of northern South America and Central America: taxonomic overview with four new species
}

\author{
MARIANA A. CHERMAN ${ }^{1,4 *}$, DANIEL S. BASÍLIO ${ }^{1}$, KLEBER M. MISE $^{1}, J^{\prime O H A N N E S ~ F R I S C H}{ }^{2}$, ANDREW \\ B.T. SMITH ${ }^{3}$ \& LÚCIA M. ALMEIDA ${ }^{1}$ \\ ${ }^{1}$ Laboratório de Sistemática e Bioecologia de Coleoptera, Departamento de Zoologia, Universidade Federal do Paraná, Caixa Postal \\ 19020, 81531-980, Curitiba, Paraná, Brazil. \\ ="basilio.dsb@gmail.com; 으ttps://orcid.org/0000-0003-3556-5880 \\ "="klebermise@yahoo.com.br; @ https://orcid.org/0000-0003-4391-9589 \\ ="lalmeida@ufpr.br; i https://orcid.org/0000-0003-4277-711X \\ ${ }^{2}$ Museum für Naturkunde, Invalidenstraße 43, 10115 Berlin, Germany. \\ ”-johannes.frisch@mfn-berlin.de; (1) https://orcid.org/0000-0002-7895-7529 \\ ${ }^{3}$ Research Division, Canadian Museum of Nature, P.O. Box 3443, Station D, Ottawa, Ontario, K1P 6P4, Canada. \\ झ"asmith@nature.ca; ○ https://orcid.org/0000-0002-8059-5133 \\ ${ }^{4}$ Laboratório de Scarabaeoidologia, Departamento de Biologia e Zoologia, Instituto de Biociências, Universidade Federal de Mato \\ Grosso, 78060-900, Cuiabá, Mato Grosso, Brazil. \\ *corresponding author: "marianabioar@gmail.com; @ https://orcid.org/0000-0001-6114-7290
}

\begin{abstract}
The biodiversity of northern South American and Central American Liogenys Guérin-Méneville, 1831 (Coleoptera: Scarabaeidae: Melolonthinae: Diplotaxini) is reviewed. Four new species are described: L. clipeosetosa Cherman, new species; L. genieri Smith \& Cherman, new species; L. granadina Cherman, new species; and L. schneiderae Cherman, new species. The male of $L$. quadridens (Fabricius, 1798) and the female of L. quadridentata Blanchard, 1851 are described for the first time. Liogenys gebieni Moser, 1921 is a new junior subjective synonym of L. macropelma Bates, 1887. The northernmost record of Liogenys is emended to Trinidad and Tobago for L. granadina Cherman, new species and L. schneiderae new species. Diplotaxis puberea cuprascens (Bates, 1887) new combination, Diplotaxis puberea puberea (Bates, 1887) new combination, and Diplotaxis pubisternis (Bates, 1887) new combination are all transferred from Liogenys to Diplotaxis Kirby, 1837. Lectotypes are designated for Liogenys gebieni Moser, 1921; Melolontha quadridens Fabricius, 1798; and Liogenys quadridentatus Blanchard, 1851. An identification key to northern South American Liogenys is presented.
\end{abstract}

Key words: Chafers, Neotropical, Scarabaeoidea, taxonomy, white grubs

\section{Introduction}

Liogenys Guérin-Méneville, 1831 is the most specious genus of Neotropical Diplotaxini (Coleoptera: Scarabaeidae: Melolonthinae) and now comprises 95 species distributed from Panama throughout most of South America to Argentina and Chile (Cherman et al. 2017, 2019, 2020, 2021). The northernmost limit of Liogenys geographical distribution is somewhat overlapped with Diplotaxis Kirby, 1837 (Vaurie 1958). Diplotaxis is together with Apogonia Kirby, 1819 the largest genus of the tribe worldwide, comprised of 237 species (Cherman et al. 2016; Delgado \& Toledo-Hernández 2020). Despite their similarities, Liogenys and Diplotaxis are easily distinguished by the following characters (relative to Diplotaxis in parenthesis): outer margin of maxilla straight, forming a right angle with the galea (curved), subapical callus of elytra situated more close to the suture than to the outer margin (callus more close to the outer margin than to the suture), base of elytral suture extended up to the midline of the scutellar margin (extended along the entire scutellar margin) and elytral suture narrowed towards the apex of elytra (uniform width along the elytra), metacoxa length equal or greater than length of ventrite II (less than), 
and pygidium generally twice as long as ventrite V (less than twice as long) (Vaurie 1958; Cherman et al. 2016). In Evans \& Smith (2009), the following Mexican species are also included in Liogenys: L. puberea cuprascens Bates, 1887; L. puberea puberea Bates, 1887; and L. pubisternis Bates, 1887, being the only Neartic Liogenys species. In a phylogenetic analysis of Diplotaxini with focus on Liogenys (Cherman et al. 2016), the unique species of Central America and northern South America included is L. macropelma Bates, 1887, while L. puberea puberea was included in Diplotaxis without a formal transference. Both L. quadridens (Fabricius, 1798) and L. quadridentata Blanchard, 1851 seem to be representatives within a complex of cryptic species, which is why they were set aside from the Cherman et al. (2016) analysis. Also, Harold (1869), Bates (1887), and Dalla Torre (1913) had suggested a synonymy between L. quadridens and L. quadridentata, but none of them formalized this nomenclatural act (Cherman et al. 2017). Liogenys quadridens seems to be well adapted to degraded habitats and was cited as an important pest of biannual crops, such as maize (Zea mays L., Poaceae) and sorghum (Sorghum spp., Poaceae) along the Colombian Caribbean region (García-Atencia et al. 2015); and was recorded in several Solanaceae plants, including tomato (Solanum lycopersicum L.) in Maracaibo, Venezuela (Morales-Valles et al. 2003). Thus, its identification needs to be accurate to design appropriate integrated pest management plans. In this work, the morphology of a large number of specimens from 14 museums was studied to resolve this species complex, and other species in this region were also revised. The purpose of this paper is to revise the Central American and northern South American Liogenys. The latter region is defined as the area north of the Amazonian basin, which consists of northern Brazil, Ecuador, Colombia, Venezuela, Guyana, Suriname, and French Guiana.

\section{Material and methods}

Material examined. A total of 300 specimens of Liogenys were studied during this work. The material is deposited in the following institutions (with acronyms following Evenhuis 2020).

AMNH—American Museum of Natural History, New York, New York, United States of America (Lee Herman)

BMNH-The Natural History Museum, London, United Kingdom (Maxwell Barclay)

CEMT—Setor de Entomologia da Coleção Zoológica, Universidade Federal de Mato Grosso, Cuiabá, Brazil (Fernando Vaz-de-Mello)

CMNC - Canadian Museum of Nature, Ottawa, Ontario, Canada (François Génier)

$\mathrm{CMNH}-$ Carnegie Museum of Natural History, Pittsburgh, Pennsylvania, United States of America (Robert Davidson)

DZUP—Coleção Entomológica Pe. J.S. Moure, Curitiba, Brazil (Lúcia M. Almeida)

FSCA - Florida State Collection of Arthropods, Gainesville, Florida, United States of America (Paul Skelley)

MLUH-Martin-Luther-Universität, Wissenschaftsbereich Zoologie, Halle (Saale), Germany (Karla Schneider)

MNHN—Muséum National d'Histoire Naturelle, Paris, France (Antoine Mantilleri)

MZUC-Universidad de Concepción, Museo de Zoologia, Concepción, Chile (Jorge Artigas)

NHMB - Naturhistorisches Museum, Basel, Switzerland (Isabelle Zuercher)

ROME - Royal Ontario Museum, Toronto, Ontario, Canada (Doug Currie \& Brad Hubley).

SDEI-Senckenberg Deutsches Entomologisches Institut, Müncheberg, Germany (Stephan Blank)

UNSM - University of Nebraska State Museum, Lincoln, Nebraska, United States of America (Brett Ratcliffe \& M.J. Paulsen)

USNM - United States National Museum of Natural History, Washington, District of Columbia, United States of America (Floyd Shockley \& M.J. Paulsen)

ZMHB-Museum für Naturkunde der Leibniz-Institut für Evolutions- und Biodiversitätsforschung, Berlin, Germany (Joachim Willers)

ZMUC_-University of Copenhagen, Zoological Museum, Copenhagen, Denmark (Alexey Solodovnikov)

Morphological study. Mouthparts and male genitalia, when available, were dissected and examined for all species. The standards for characters used in the species descriptions follow Lawrence (1999), Cherman \& Almeida (2015) and Cherman et al. (2016, 2017). 
Species descriptions and redescriptions are presented following the guidelines of Ratcliffe (2013). The author of three of the new species contained in this manuscript is the first author of this work, Mariana Cherman, who was responsible for satisfying all availability criteria. Andrew Smith and Mariana Cherman are authors of one species that was co-discovered late in the project.

Labels of the type material are arranged in sequence from top to bottom, where the data for each label are within double quotes (“"), a slash (/) separates the rows and "," separates labels. Information between brackets ([ ]) provides additional details written on the labels.

The geographical distribution is based on specimens we examined. All previously published records should be considered questionable until they are verified using voucher specimens due to our discovery of new cryptic species. Shapefiles from the biogeographical regionalization of the Neotropical region (Morrone 2014) by Löwenberg-Neto (2014) were used to perform the distributional map for the geographical distribution of the new species.

The identification key to the Liogenys presented in this work is a complementary tool to the interactive key to New World Diplotaxini available at: http://keys.lucidcentral.org/keys/v3/diplotaxini/ (Cherman et al. 2019). This digital project includes all Liogenys species recently revised by M.A.C. Changelog files provided at the main page of the key enables anyone to track the changes from the original database (Cherman et al. 2017) and to use them for further studies. For more information concerning Lucid keys, visit www.lucidcentral.org.

\section{Key to Liogenys species from northern South America and Central America}

1. Clypeus bidentate (Fig. 5A-B), only anterior margin of clypeus indented; distal maxillary palpomere evenly convex, without a

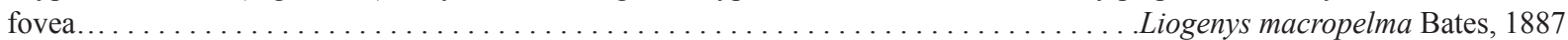
Clypeus quadridentate (Fig. 1A-D), anterior and lateral margin of clypeus indented; distal maxillary palpomere with an

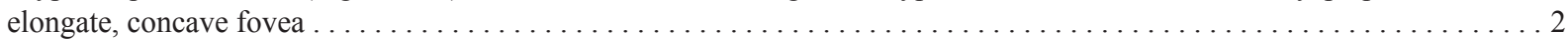

2. Angle between lateral and anterior teeth on clypeus slightly or strongly acute (Fig. 1C); males with lateral expansion along the

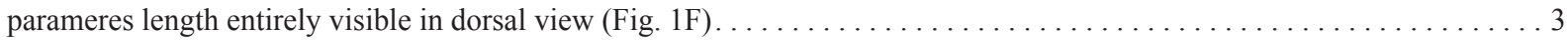
Angle between lateral and anterior teeth on clypeus right or obtuse (Fig. 1A); males with lateral expansion along the parameres

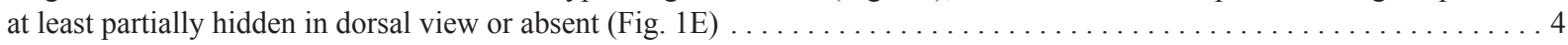

3. Frons and clypeus glabrous (Fig. 1C-D); angle between lateral and anterior teeth on clypeus strongly acute; pronotum moderate coarsely punctate; males with pygidium convex medially (Fig. 7D) and females with pygidium strongly inflated (Fig. 7E) ...

Liogenys quadridentata Blanchard, 1851 Frons and clypeus with bristles (Fig. 2C); angle between lateral and anterior teeth on clypeus slightly acute; pronotum strongly coarsely punctate; pygidium almost flat, sometimes slightly depressed medially (Fig. $2 \mathrm{~F}) \ldots \ldots \ldots \ldots \ldots \ldots$

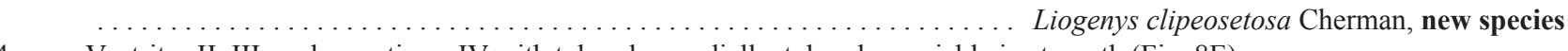
Ventrites II, III, and sometimes IV with tubercles medially, tubercles variable in strength (Fig. 8E) . .............

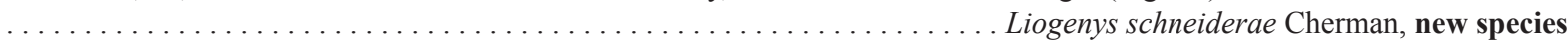

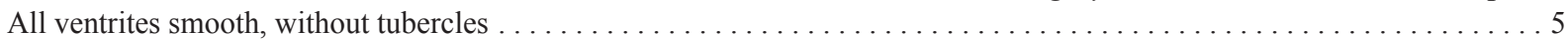
Clypeal emargination clearly wider than the dorsal diameter of one eye (Fig. 1B). . . . Liogenys quadridens (Fabricius, 1798) Clypeal emargination as wide as or narrower than the dorsal diameter of one eye (Fig. 4B) $\ldots \ldots \ldots \ldots \ldots \ldots \ldots$ Body and pronotum purplish brown, strongly darker than elytra; clypeal emargination strongly angulate; pronotum with anterolateral margin reflexed (Fig. 3C); pygidium without sexual dimorphism, weakly convex in both sexes ........... Liogenys genieri Smith \& Cherman, new species Body and pronotum reddish brown, slightly darker than elytra; clypeal emargination rounded; pronotum with anterolateral margin not reflexed, pygidium weakly convex in males and strongly convex to inflated in females . . . . . . . . . . . .

Liogenys granadina Cherman, new species

\section{Liogenys clipeosetosa Cherman, new species}

Figs. 2, 9 .

Type material. Holotype male, labeled: [green typeset] "Venezuela / F. Kummerow S.", [red typeset and handwritten] "LIOGENYS / CLIPEOSETOSA / HOLOTYPE / Cherman M. A.", genitalia mounted (ZMHB). Paratypes (10) all bearing the label [yellow, typeset and handwritten] "LIOGENYS / CLIPEOSETOSA / PARATYPE / Cherman M. A.". Six female paratypes bearing the same data of the holotype (ZMHB). Three female paratypes with the label: [green, outlined, typeset] "Hist. Coll. (Coleoptera) / Nr. 24131 / Liogenys quadridens Burm. / Columb., Moritz. / Zool. Mus. Berlin" (ZMHB). One female paratype with the data: [white, typeset] "VENEZUELA: Lara / 20 km.E. Carora / 24-VI-1976 / Holotype and nine paratypes deposited at ZMHB. One paratypes at USNM. 

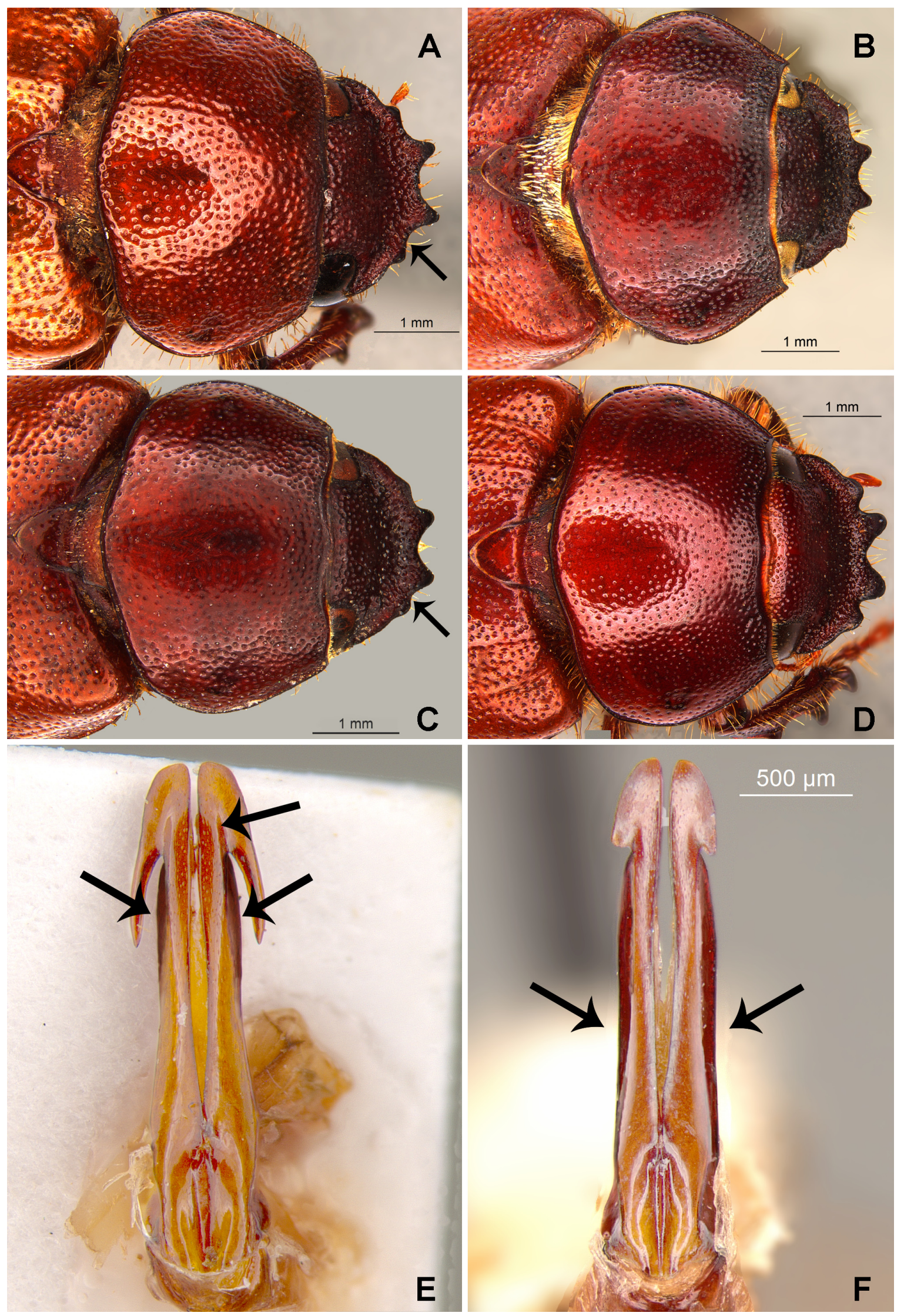

FIGURE 1. Clypeus and pronotum: Liogenys quadridens (Fabricius, 1798) A) male, B) female; L. quadridentata Blanchard, 1851 C) male, D) female. Parameres of E) L. quadridens and F) L. clipeosetosa Cherman new species. Black arrows indicate: A, C) angle between anterior and lateral teeth on clypeus; lateral expansion along the parameres F) entirely visible or E) partially hidden, E) disc of subapical portion and base of apex elevated. 


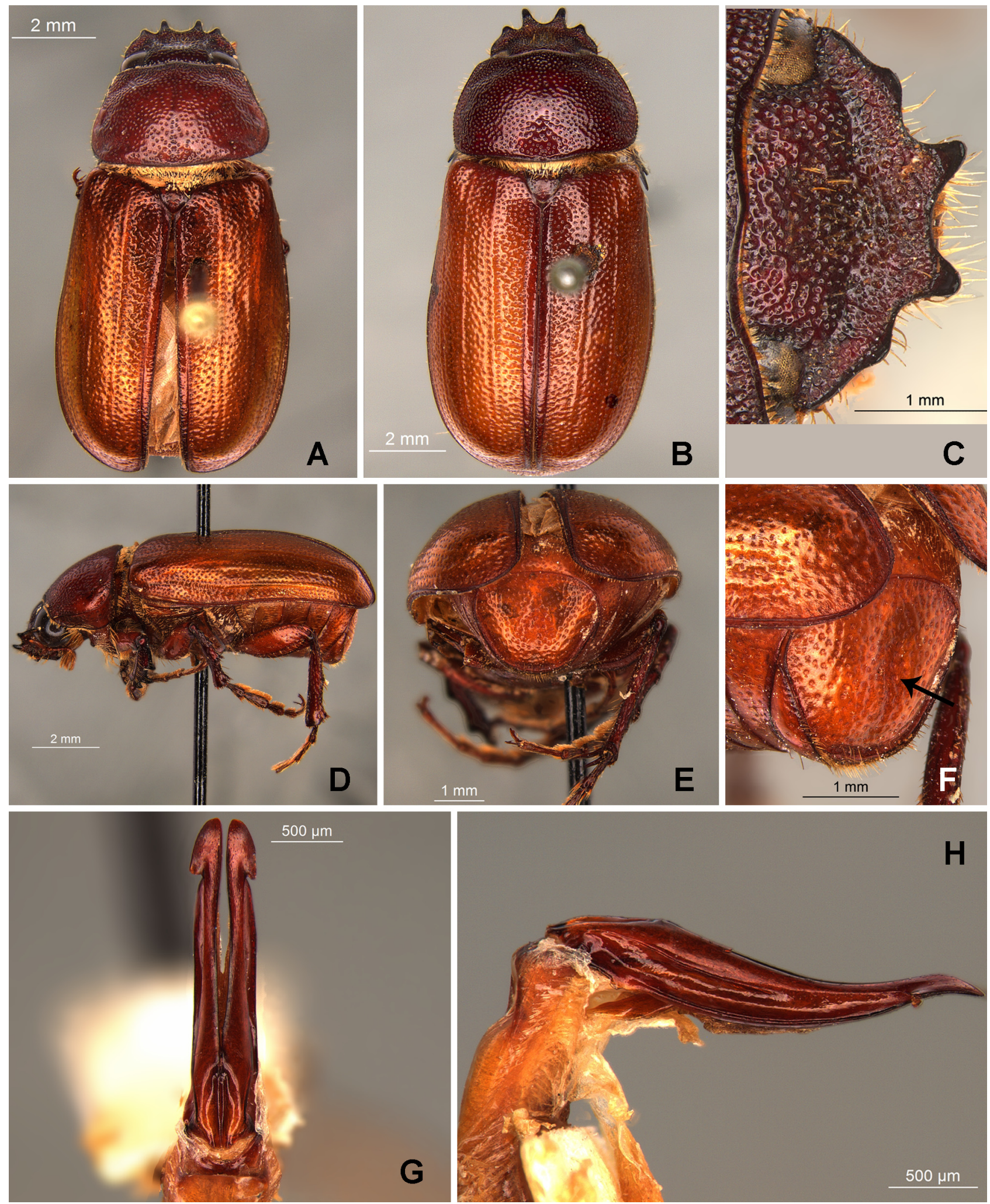

FIGURE 2. Liogenys clipeosetosa Cherman new species male holotype views: A) dorsal, B-C) dorsal and clypeus of female, D) lateral, E) posterior, F) posterolateral of pygidium, and parameres $G$ ) dorsal and H) lateral. Black arrow indicates the F) medial depression of pygidium.

Additional material. Three females (FSCA) were port interceptions from Gulfport, Mississippi, United States of America in Musa (Musaceae) (bananas, plantains, etc.) originating from Colombia. We examined photographs of these specimens provided by John Leavengood (United States Department of Agriculture, Tampa, Florida, United 
States of America). No specific locality was available within Colombia and it is likely that these specimens were attracted to lights during the packing or loading of this commodity.

Diagnosis. Body light brown; elongate (Fig. 2A-B), elytra light brown to yellowish brown, pronotum reddish brown, head darker; clypeus quadridentate; clypeal emargination deep, rounded, and wide; anterior teeth sometimes twice the length of the lateral teeth (Fig. 2C); distance between lateral and anterior clypeal teeth longer than basal width of one anterior tooth; angle between lateral and anterior clypeal teeth $90^{\circ}$ or acute; clypeus and part of the frons with bristles; pronotum roughly punctate; pronotal corners rounded or subangulate; mesotibia quadrate in cross section (Fig. 2D); pygidium flat or slightly convex, depressed medially (Fig. 2E-F), pygidial disc with short bristles throughout, bristles longer on apex; males with protarsomere II up to twice the length of protarsomere I in dorsal view; parameres elongate, inner margins straight; lateral expansion along the parameres length entirely visible in dorsal view; apex harpoon-shaped, lateral spine projected backwards, slightly convergent compared to the outer margin of the parameres; spine length slightly longer than the apex, subapical and part of the apex not elevated on midline (Figs. 1E, 2G).

Holotype. Male. Length: $12.0 \mathrm{~mm}$, width: $5.8 \mathrm{~mm}$. Light brown. Head: darker than pronotum, distance between eyes less than twice the width of one eye; frons equal in length to clypeus; frontoclypeal surface with bristles, clypeal emargination deep, rounded, and wide; outer sides of anterior teeth parallel; outer margin of anterior teeth shorter than the eye in dorsal view; clypeus convex laterally and strongly produced forming a conspicuous, tooth-like projection; distance between lateral and anterior teeth longer than basal width of one anterior tooth, distance between lateral tooth and anterior margin of eye equal to one eye length, angle between anterior and lateral teeth approximately $90^{\circ}$; canthus not exceeding the outer margin of the eye; distal maxillary palpomere, maximum width more than twice the width at apex; fovea shallow, extending past the transverse midline of the palpomere; antenna with 10 antennomeres, club lighter in color and longer than funicle. Thorax: pronotal anterior margin slightly produced medially, undulate and flanged; anteriorly and on posterolateral surface depressed, sulcate medially; pronotal disc glabrous, punctures sparse medially and rugose on anterior margin; pronotal posterior corners rounded; hypomere with few long bristles; mesepisternum scaly; anterior portion and sides of metaventrite with bristles; distance between mesocoxae and metacoxae nearly twice the width of the metacoxa; scutellum ogival, sparse punctures. Elytra: shiny, uniform yellowish brown, lighter in color than pronotum; elytra near three times the length of pronotum; elytral suture slightly darker than elytron and not elevated; all four elytral ridges weakly defined. Legs: procoxa with long bristles on infra-carinal surface, fine scales and short bristles on outer surface; three protibial teeth, middle and apical teeth equal in size, distance between basal and middle teeth longer than between middle and apical teeth; mesofemur with a row of long bristles on anterior and posterior margins, mesotibia quadrate in cross section, surface coarsely sculptured, mesotibia with two transverse carinae, the apical carina incomplete; metacoxa with bristles throughout; basal articular lobe of metacoxa produced beyond the outer margin of trochanter; inner margin of metatibia carinate and produced on apex, apical inner surface with scattered bristles, metatibial surface coarsely sculptured; metatibial transverse carina and discontinuous longitudinal carina present posteriorly; protarsomere II elongate; protarsomeres and mesotarsomeres I-IV enlarged, protarsomeres slightly wider than mesotarsomeres, more than twice the width of metatarsomeres; metatarsomere I and metatarsomere II equal in length; claw bifid, symmetrical, outer tooth of a claw longer and as wide as the inner tooth; distance between teeth shorter than the inner tooth. Abdomen: disc of ventrites with sparse bristles; propygidium with bristles, pygidium flat, subtrapezoidal, wide, pygidial width exceeding distance between spiracles of propygidium; pygidial disc glabrous except for a few bristles on apex, pygidial disc coarsely punctate; depressed medially; pygidial apex quadrate. Parameres: basal region slightly wider than both sections of the parameres at its midline; parameral split at $2 / 3$ the length of the basal region; inner margins straight; lateral expansion along the parameres length entirely visible in dorsal view; apex harpoon-shaped, laterally expanded and blunt projected. Parameres concave in lateral view (Fig. 2H).

Variation. Female paratypes. Length: $11.2-12.6 \mathrm{~mm}$; width $5.4-6.3 \mathrm{~mm}$. As the holotype except pygidial apex rounder, wider and somewhat convex, not depressed medially. Some females have the clypeal teeth noticeable longer. One female from Venezuela has a subtrapezoidal pygidium.

Etymology. Adjective in the nominative singular. From the Latin clipeus (clypeus) + Latin setosus, from seta ("bristle").

Type locality. Venezuela.

Geographical distribution. COLOMBIA, VENEZUELA (Lara).

Remarks. Liogenys clipeosetosa Cherman, new species resembles L. quadridens in the body color and size, shape of the quadridentate clypeus, pygidium, and somewhat in the shape of the male parameres. Liogenys clipeosetosa differs (L. quadridens in parenthesis) in the clypeus with bristles (clypeus glabrous), fovea of the distal maxillary palpomere shallow, surface almost flat (fovea deep); pronotal anterior margin flanged (flange less 
conspicuous or absent); pronotum depressed anteriorly and on posterolateral surface, sulcate medially (not as so); pronotal disc roughly punctate mainly on anterior margin (pronotal disc less coarse and uniformly punctate); males with the protarsomere II longer than wide (as wide as it is long); apex of parameres entirely flat and lateral expansion along the parameres length entirely visible in dorsal view (subapical and proximal part of the apex elevated medially and lateral expansion of parameres partially hidden, visible from the midline up to the subapical portion).

\section{Liogenys genieri Smith \& Cherman, new species}

Figs. 3, 9.

Type material. Holotype male, labeled: [white, typeset] "VENEZUELA: Guarico, Hato / Flores Morades, $45 \mathrm{~km} \mathrm{~S}$ / Calabozo, 8.57N, 67.58W / Galry Forest \#2, 75 m / 24-26June 1989, uv light / M. Epstein \& M. Rodiguez”, [red, typeset and handwritten] "LIOGENYS / GENIERI / SMITH \& CHERMAN / HOLOTYPE", genitalia mounted (USNM). Paratypes (8), all bearing the label [yellow, typeset and handwritten] "LIOGENYS / GENIERI / SMITH \& CHERMAN / PARATYPE": One male and six females with the same data as the holotype (one male and one female at CMNC, two females at DZUP, three females at USNM). One male with the data: [white, typeset] "VENEZUELA: Guarico / Hato Masaguaral / (44km S Calabozo) / May 3-10 1985 / Menke \& Carpenter" (USNM). Each female paratype of DZUP with the voucher: [white typeset] "DZUP / 402748" and "DZUP / 402749".

Holotype and four paratypes deposited at USNM. Two paratypes at CMNC. Two paratypes at DZUP.

Diagnosis. Body light brown, elongate, sides almost parallel; elytra light brown; pronotum reddish brown (Fig. 3A); clypeus quadridentate; clypeal emargination deep, angulate, and narrow; distance between lateral and anterior clypeal teeth approximately equal to basal width of one anterior tooth; angle between lateral and anterior clypeal teeth approximately $90^{\circ}$; pronotal corners rounded (Fig. 3B); mesotibia subquadrate in cross section; pygidium slightly convex; pygidial disc glabrous, with scattered bristles on apex (Fig. 3D); in males protarsomere II more than twice the length of protarsomere I in dorsal view (Fig. 3C); parameres more than six times the length of their apex; lateral expansion along the parameres only seen subapically; inner margins convergent; apex expanded with backward-facing spine weakly projected, spine length less than one-third length of apex (Fig. 3E).

Holotype. Male. Length: $9.6 \mathrm{~mm}$, width: $4.6 \mathrm{~mm}$. Light brown. Head: distance between eyes nearly twice the width of one eye; frons equal in length to clypeus; clypeal emargination deep, angulate, and wide; outer sides of anterior teeth parallel; outer margin of anterior teeth shorter than the eye in dorsal view; clypeus convex laterally and strongly produced forming a conspicuous tooth-like projection; distance between lateral and anterior teeth approximately equal to basal width of one anterior tooth, distance between lateral tooth and anterior margin of eye approximately equal to one eye length, angle between anterior and lateral teeth approximately $90^{\circ}$; canthus not exceeding the outer margin of the eye; distal maxillary palpomere, maximum width twice the width at apex; antenna with 10 antennomeres, club lighter in color and longer than funicle. Thorax: pronotal anterior margin slightly produced medially, undulate, and flanged; disc glabrous, punctures moderately dense and coarse; anterolateral margin reflexed; pronotal posterior corners rounded; hypomere with long bristles; mesepisternum scaly; anterior portion and sides of metaventrite with bristles; distance between mesocoxae and metacoxae nearly twice the length of the metacoxa; scutellum triangular with sparse, coarse punctures. Elytra: shiny, uniform light brown, lighter in color than the pronotum; elytra near three times the length of pronotum; elytral suture darker than the elytron and weakly elevated; all four elytral ridges weakly defined. Legs: procoxa with abundant, thin and long scales, short scales on outer surface; three protibial teeth, middle and apical teeth equal in size, distance between basal and middle teeth longer than between middle and apical teeth; protibial spur present; mesofemur with a row of long bristles on anterior and posterior margins, mesotibia subquadrate in cross section, surface coarsely sculptured on outer margin, mesotibia with two transverse carinae, the apical carina incomplete; metacoxa with bristles throughout, basal articular lobe of metacoxa produced beyond the outer margin of trochanter; inner margin of metatibia straight, carinate, and produced on apex, apical inner surface with bristles, metatibial surface coarsely sculptured; metatibial transverse carina weakly defined, only present posteriorly; protarsomere II elongate; protarsomeres and mesotarsomeres I-IV enlarged, protarsomeres slightly wider than the mesotarsomeres and two times wider than the metatarsomeres; metatarsomere I slightly shorter than metatarsomere II; claw bifid, symmetrical, outer tooth of a claw longer and as wide as the inner tooth; distance between teeth shorter than the inner tooth. Abdomen: disc of ventrites with bristles; propygidium with bristles, pygidium weakly convex, subquadrate, wide; pygidial width approximately equal to distance between spiracles of propygidium; pygidial disc glabrous except for a few bristles on apex, pygidial disc coarsely punctate; pygidial apex oval. Parameres: basal region dorsally narrowed, equal to both sections of the 


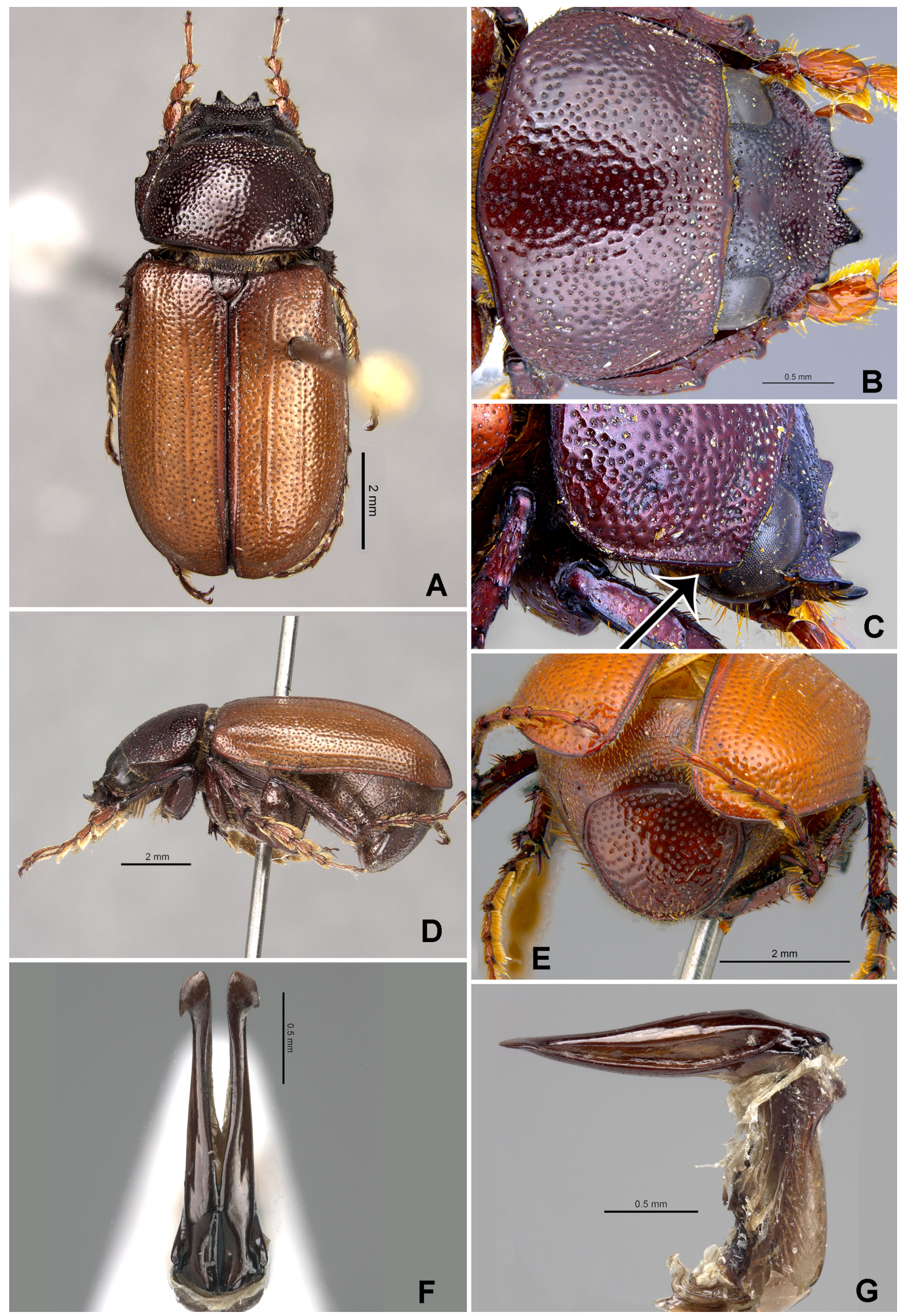

FIGURE 3. Liogenys genieri Smith \& Cherman new species male holotype views: A) dorsal, B) clypeus and pronotum, C) detail of anterolateral margin of pronotum reflexed, D) lateral, E) pygidium, and parameres E) dorsal and F) lateral. 
parameres at its midline; parameral split at $2 / 3$ the length of the basal region; inner margins slightly convergent; parameres more than six times the length of their apex; apex harpoon shaped; laterally expanded with backward-facing spine weakly projected straight downward, spine length less than one-third length of apex. Parameres in lateral view straight, not coplanar (Fig. 3F).

Variation. Female length: 10.2-11.2 mm, width $5.0-5.6 \mathrm{~mm}$. Females as the holotype except in the size; pronotum wider, with anterolateral margin distinctly reflexed; maximum width of distal maxillary palpomere slightly wider than at apex. Male length: 9.4-9.6 mm, width 4.0-4.8 $\mathrm{mm}$. Males as the holotype except in the punctures of pronotum slightly less dense; protibial teeth sharper and longer (worn in holotype).

Etymology. This species is named after François Génier, scarab taxonomist from the CMNC, in appreciation for his help in photographing specimens for this paper.

Type locality. Hato Masaguaral, Guárico, Venezuela $\left(8.57^{\circ} \mathrm{N}, 67.58^{\circ} \mathrm{W}\right)$.

Geographical distribution. VENEZUELA (Guárico).

Remarks. Liogenys genieri Smith \& Cherman, new species resembles L. clipeosetosa in the body color and size, shape of the quadridentate clypeus, head and pronotum coarsely punctate, anterior teeth of clypeus long, anterior and lateral teeth forming approximately $90^{\circ}$ angle, and posterior corners of pronotum rounded. Males in both species have parameres very long, more than five times the apical length, and apex laterally weakly projected. Liogenys genieri differs (L. clipeosetosa in parenthesis) in the frontoclypeal surface without bristles (with bristles); clypeal emargination angulate, narrower (rounded, wider); pronotum with anterolateral margin reflexed (not as so); apex of pygidium oval (quadrate); males with parameres slightly shorter, lateral expansion along the parameres not visible dorsally and straight in lateral view (lateral expansion entirely visible dorsally).

\section{Liogenys granadina Cherman, new species}

Figs. 4, 9 .

Type material. Holotype male, labeled: [white handwritten] "N. Grenada / Cartagena / coll[?] Chev.", [red typeset and handwritten] "LIOGENYS / GRANADINA / HOLOTYPE / Cherman M. A.", genitalia mounted (ZMHB). Paratypes (45), all bearing the label [yellow, typeset and handwritten] "LIOGENYS / GRANADINA / PARATYPE / Cherman M. A.”: One male bearing: [white handwritten] "Venezuela / Orinoco river [?]", [white typeset] "Liogenys / [handwritten] quadri- / dens F / [typeset] det. G. Frey, 1968", genitalia mounted (ZMHB). One female with the labels: [white handwritten] "nov. grenada", [white typeset] "Liogenys / [handwritten] quadridens / Mos / typeset] det. G. Frey, 1968" (ZMHB). One male with the data: [white, typeset] "TRINIDAD: St. George Co. / Monos Island. $10^{\circ} 42^{\prime} \mathrm{Nx} / 61^{\circ} 41^{\prime} \mathrm{W} .31$ MAY 1987 / ROM\#872012. M.L. Pickles" (ROME). One male with the data: [pink, handwritten] "Columbia", [white, typeset] "Pascoe / Coll. / 93-60", [white, handwritten] "Telea / 4dentata / [illegible]" (BMNH). One male with the data: [green, handwritten] "Columbia / Lebas.", [light blue, handwritten] "4-dentatus / Blanch. Cat. / p. 168", [white, typeset] "So named / in Reiches / Collection. / C.W.", [light blue, handwritten] "2259", [green, handwritten] " 0 ", [white, typeset] "67.45", [white, handwritten] "4-dentatus. / Blanch. Dej. / brevicollis, / Reich. / Carthagena" (BMNH). Seven males and three females with the data [white, typeset] "VENEZUELA, Guar. / 12kmS Carabozo / 6 II 1969", [white, typeset] "P\&PSpangler / Est. Bio. Los / Llanos uv lite" (two males and one female at CMNC, two males and one female at DZUP, three males and one female at USNM). Paratypes of DZUP with the sequence of voucher numbers: [white typeset] "DZUP / 402750" to "DZUP / 402752". Ten males and seven females with the data [white, typeset] "VENEZUELA / Guar. 12 Km S. / Carabozo / II-6-12-1969 / P.\&P. Spangler", [white, typeset] "Est. Biologica / Los Llanos / Black Light" (three males and two females at CMNC, two males and two females at CEMT, five males and three females at USNM). Five males and two females with the data [white, typeset] "VENEZUELA, Guar. / 12kmS Carabozo", [white, typeset] "6-12 II 1969 / P\&PSpangler / BiolSta uv lite" (USNM). One male with the data [white, typeset] "VENEZUELA, Guar. / 12kmS Carabozo", [white, typeset] "6-12 II 1969 / P\&PSpangler" (USNM). One female with the data [white, typeset and handwritten] "Cd Bolivar / 23-6 Venez", [white, typeset] "EA Klages / Collector" (USNM). One female with the data [white, typeset and handwritten] "Cd Bolivar / 20-6 Venez", [white, typeset] "EA Klages / Collector", [white, typeset and handwritten] "Liogenys / quadri- / dens / det.G.Frey,1968" (USNM). One female with the data [white, typeset and handwritten] "Cd Bolivar / 20-6 Venez", [white, typeset] "EA Klages / Collector" (USNM). One female with the data [white, typeset] "VENEZUELA:Guarico / Hato Masaguaral / (44km S Calabozo) / May 3-10 1985 
/ Menke \& Carpenter" (USNM). Two females with the data [white, typeset and handwritten] "VENEZUELA / Maracay / 450 m. / 15.VI.1949. / H.E. Box" (USNM).

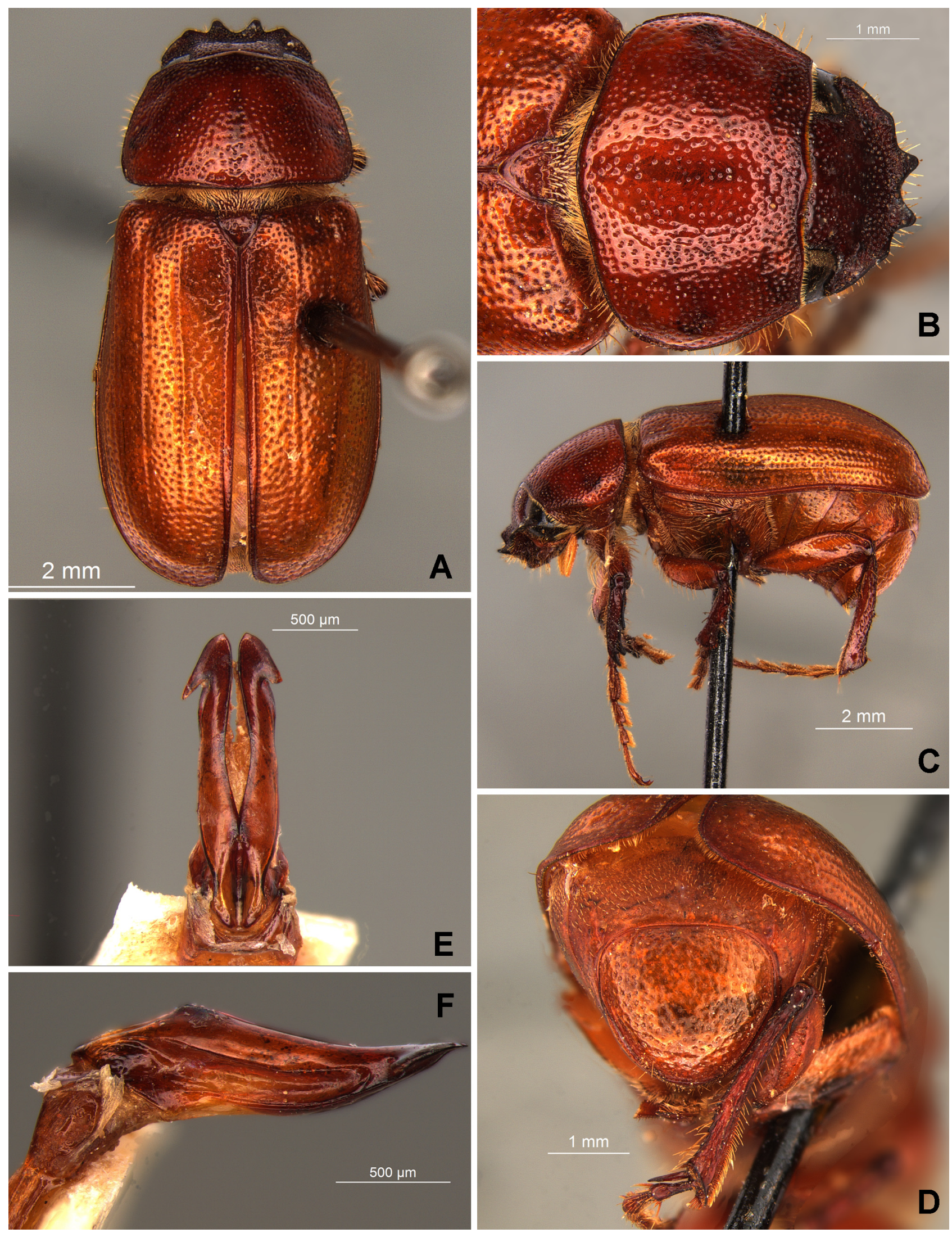

FIGURE 4. Liogenys granadina Cherman new species male holotype views: A) dorsal, B) clypeus and pronotum, C) lateral, D) pygidium, and parameres E) dorsal and F) lateral. 
Holotype and two paratypes deposited at ZMHB. Two paratypes at BMNH. Eight paratypes at CMNC. Three paratypes at DZUP. Four paratypes at CEMT. One paratype at ROME. Twenty-five paratypes at USNM.

Diagnosis. Body light brown, elongate, sides almost parallel; elytra light brown; pronotum reddish brown (Fig. 4A); clypeus quadridentate; clypeal emargination deep, rounded, and narrow; distance between lateral and anterior clypeal teeth longer than basal width of one anterior tooth; angle between lateral and anterior clypeal teeth $90^{\circ}$ or slightly acute; pronotal corners rounded (Fig. 4B); mesotibia quadrate in cross section; pygidium convex; pygidial disc glabrous, with scattered bristles on apex (Fig. 4D); in males protarsomere II more than twice the length of protarsomere I in dorsal view (Fig. 4C); parameres four times the length of their apex; lateral expansion along the parameres only seen subapically; inner margins convergent; apex harpoon shaped, lateral spine projected at approximately a $45^{\circ}$ angle, spine length as long as the apex (Fig. 4E).

Holotype. Male. Length: $9.2 \mathrm{~mm}$, width: $4.6 \mathrm{~mm}$. Light brown. Head: distance between eyes nearly twice the width of one eye; frons equal in length to clypeus; clypeal emargination deep, rounded, and narrow; outer sides of anterior teeth parallel; outer margin of anterior teeth shorter than the eye in dorsal view; clypeus convex laterally and strongly produced forming a conspicuous tooth-like projection; distance between lateral and anterior teeth longer than basal width of one anterior tooth, distance between lateral tooth and anterior margin of eye longer than one eye length, angle between anterior and lateral teeth approximately $90^{\circ}$; canthus not exceeding the outer margin of the eye; distal maxillary palpomere not seen; antenna with 10 antennomeres, club lighter in color and longer than funicle. Thorax: pronotal anterior margin moderately produced medially, undulate and flanged; maximum length of pronotum exceeding the length of tarsomeres I-III combined; disc glabrous, punctures very sparse and coarse; pronotal posterior corners rounded; hypomere with long bristles; mesepisternum scaly; anterior portion and sides of metaventrite with bristles; distance between mesocoxae and metacoxae nearly twice the length of the metacoxa; scutellum triangular with sparse, coarse punctures, mainly at the sides. Elytra: shiny, uniform light brown, slightly lighter in color than the pronotum; elytra more than three times longer than the pronotum; elytral suture darker than the elytron and weakly elevated; all four elytral ridges weakly defined. Legs: procoxa with abundant, thin and long scales, outer surface with short scales; three protibial teeth, middle and apical teeth equal in size, distance between basal and middle teeth longer than between middle and apical teeth; protibial spur present; mesofemur with a row of long bristles on anterior and posterior margins, mesotibia subquadrate in cross section, surface coarsely sculptured on outer margin, mesotibia with two transverse carinae, the apical carina incomplete; metacoxa with bristles throughout, basal articular lobe of metacoxa produced beyond the outer margin of trochanter; inner margin of metatibia carinate and produced on apex, apical inner surface with sparse bristles, metatibial surface coarsely sculptured; metatibial transverse carina present posteriorly; protarsomere II elongate; protarsomeres and mesotarsomeres I-IV enlarged, protarsomeres wider than mesotarsomeres and two times wider than metatarsomeres; metatarsomere I slightly shorter than metatarsomere II; claw bifid, outer tooth of a claw longer and as wide as the inner tooth; distance between teeth shorter than the inner tooth. Abdomen: disc of ventrites with bristles; propygidium with bristles, pygidium convex, subquadrate, wide; pygidial width exceeding distance between spiracles of propygidium; pygidial disc glabrous and apex with few bristles, pygidial disc coarsely punctate; pygidial apex subquadrate. Parameres: basal region dorsally narrowed, equal to both sections of the parameres at its midline; parameral split at $2 / 3$ the length of the basal region; parameres four times the length of their apex; inner margins convergent; lateral expansion along the parameres only seen subapically; apex harpoon-shaped, lateral spine projected straight, at approximately a $45^{\circ}$ angle, spine length as long as the apex. Parameres concave in lateral view (Fig. 4F).

Variation. Female length: 9.5-11.4 mm, width $4.8-5.4 \mathrm{~mm}$. Females as the holotype except in the size, head, and pronotum darker than elytra; pronotum wider, with pronotal corners obsolete; maximum width of distal maxillary palpomere slightly wider than at apex; fovea deep, extending up to the transverse midline of the palpomere; scutellum ogival. Male length: $8.4-10.2 \mathrm{~mm}$, width $4.2-5.0 \mathrm{~mm}$. Males as the holotype except in the scutellum ogival; punctures of pronotum and tibiae less marked; elytral suture unicolored with the elytron; ventral expansion of the outer margins of the parameres more apparent.

Etymology. This species is named after Nueva Grenada, a defunct nation corresponding to present-day Colombia and parts of many other countries in South America (Brookes 1819). This name should be considered an adjective in the nominative singular.

Type locality. Nueva Grenada (Republic of New Grenada, today a region that comprises Panama, many South American countries, and the total territory of Colombia).

Geographical distribution. TRINIDAD AND TOBAGO (Saint George), COLOMBIA (Cartagena), VENEZUELA (Guaricó, Maracay). 
Remarks. Liogenys granadina Cherman, new species resembles L. quadridens in the shape of the quadridentate clypeus and of the pygidium. However, L. granadina is smaller than L. quadridens; the distance between anterior and lateral clypeal teeth is shorter; and in the pronotal corners are defined (obsolete in L. quadridens).

Frey (1969) considerated specimens of L. granadina as being L. quadridens, judging by his description in the key, one of the two parameres illustration (the other one corresponds to L. quadridens), and because two paratypes (USNM and ZMHB) bear his determination label. Moreover, Frey (1969) refers to a specimen from Pernambuco, Brazil, which was found at the NHMB. This Brazilian specimen was identified as Liogenys piauiensis Cherman, 2017 by Cherman et al. (2019).

There are three specimens in the USNM that were intercepted at the port of Miami, Florida on 1 May 1964 with no other information on the host or origin. This indicates that some previous port interceptions or pest reports for $L$. quadridens possibly included or even all of them are specimens of L. granadina.

\section{Liogenys macropelma Bates, 1887}

Figs. 5, 9.

Liogenys macropelma Bates, 1887: 155 (original description); Nonfried 1892: 268 (checklist); Dalla Torre 1913: 318 (checklist); Blackwelder 1944: 227 (checklist); Frey 1969: 42 (key); United States Department of Agriculture 1971: 335; 1974: 28 (natural history); Evans 2003: 210 (checklist); Evans \& Smith 2009: 179 (checklist); Krajč́́k 2012: 145 (checklist); Cherman et al. 2017: 14, 16, 69, 86 (taxonomy); 2019: 18, 64 (taxonomy), 53-55 (redescription).

Liogenys gebieni Moser, 1921: 140 (original description); Blackwelder 1944: 227 (checklist); Frey 1969: 41 (key); Evans 2003 : 209 (checklist); Evans \& Smith 2009: 178 (checklist); Krajčík 2012: 145 (checklist). New junior subjective synonym.

Type material examined. Liogenys macropelma male lectotype (MNHN): [white typeset] "V. de Chiriqui, / 25-4000 ft. / Champion.", [white handwritten] "Liogenys / macropelma / Bates \$’", [red typeset] "SYNTYPE", [white handwritten] "micropygus", [white, outlined in red, typeset] "LECTOTYPE / Liogenys macropelma / Bates, 1887 / Cherman M. A. 2015". Genitalia mounted. Six males with the same labels as the lectotype, plus the label: [white, outlined in red, typeset] "PARALECTOTYPE / Liogenys macropelma / Bates, 1887 / Cherman M. A. 2015". One female with one different label: [white handwritten] "Liogenys / macropelma / Bates \%". Six male and one female paralectotypes (BMNH): [white, typeset] "V. de Chiriqui, / 25-4000 ft. / Champion.", [white, typeset and handwritten] "B.C.A.Col.II. (2) / Liogenys / macropelma". One male paralectotype also has the labels: [round, white with red border] "Type", [white, typeset] "Sp. figured.".

Liogenys gebieni male lectotype, present designation (ZMHB): [white typeset] "Columbien / LaGarita [Los Patios, Norte de Santander] (Gebirge [mountains]) / W. Fritsche / leg. 1912" [genitalia mounted on the label], [white handwritten] "Isonychus [misspelled Liogenys] / gebieni / Typen Mos.", [red typeset] "TYPUS", [white typeset] "Liogenys / gebieni / Mos. ", [white, outlined in red, typeset and handwritten] "LIOGENYS / GEBIENI / Moser, 1921 / LECTOTYPE / Des. Cherman M. A.”. One female paralectotype with the same labels as the lectotype, plus the label: [white, outlined in red, typeset] "PARALECTOTYPE / Des. Cherman M. A. [handwritten] LIOGENYS / GEBIENI Mos.".

Additional material examined. PANAMA. Colón: Coco Solo, 21.V.1976, B.C. Ratcliffe, 10 males, 20 females (UNSM); Coco Solo Hospital, V.1981, 2 males (UNSM); Fort Gulich, 17.V.1976, at lights, B.C. Ratcliffe, 1 male, 2 females; IV.1981, at lights, 5 males (UNSM); Fort Sherman, 26.IV.1980, D. Engleman, 1 female (UNSM). Panamá: Balboa, 16-17.V.1977, light, H.\&A. Howden, 3 males, 1 female (CMNC); 19.VI.1977, H.\&A. Howden, 1 male (CMNC); Corazal, 27.IV.1911, A. Busck, 2 males (USNM); Curundú, 8.V.1972, R.\&E. Froeschner, 1 male (USNM); Diablo Heights, 3.V.1971, W.E. Bivin, 1 male, 1 female (USNM); Fort Clayton, 15.V.1961, C.E. Yunker, 8 males, 2 females (CNCI); Fort Clayton, V.1961, C.E. Yunker, 1 male (CMNC); La Sabanas, Panama City, IV.1927, at light, J. Zetek, 7 males, 19 females (USNM); Paraiso, 24.IV.1911, A. Busck, 2 males, 1 female (USNM); Punta Paitilla, Panama City, 859'N, 79³1 'W, 17.V.1970, H. Hespenheide, 1 male (CMNC); Trivoli Hotel, Panama City, 15.IV.1967, H. Hespenheide, 1 male (CMNC).

Geographical distribution. PANAMA (Chiriquí, Colón, Panamá), COLOMBIA (Norte de Santander). 

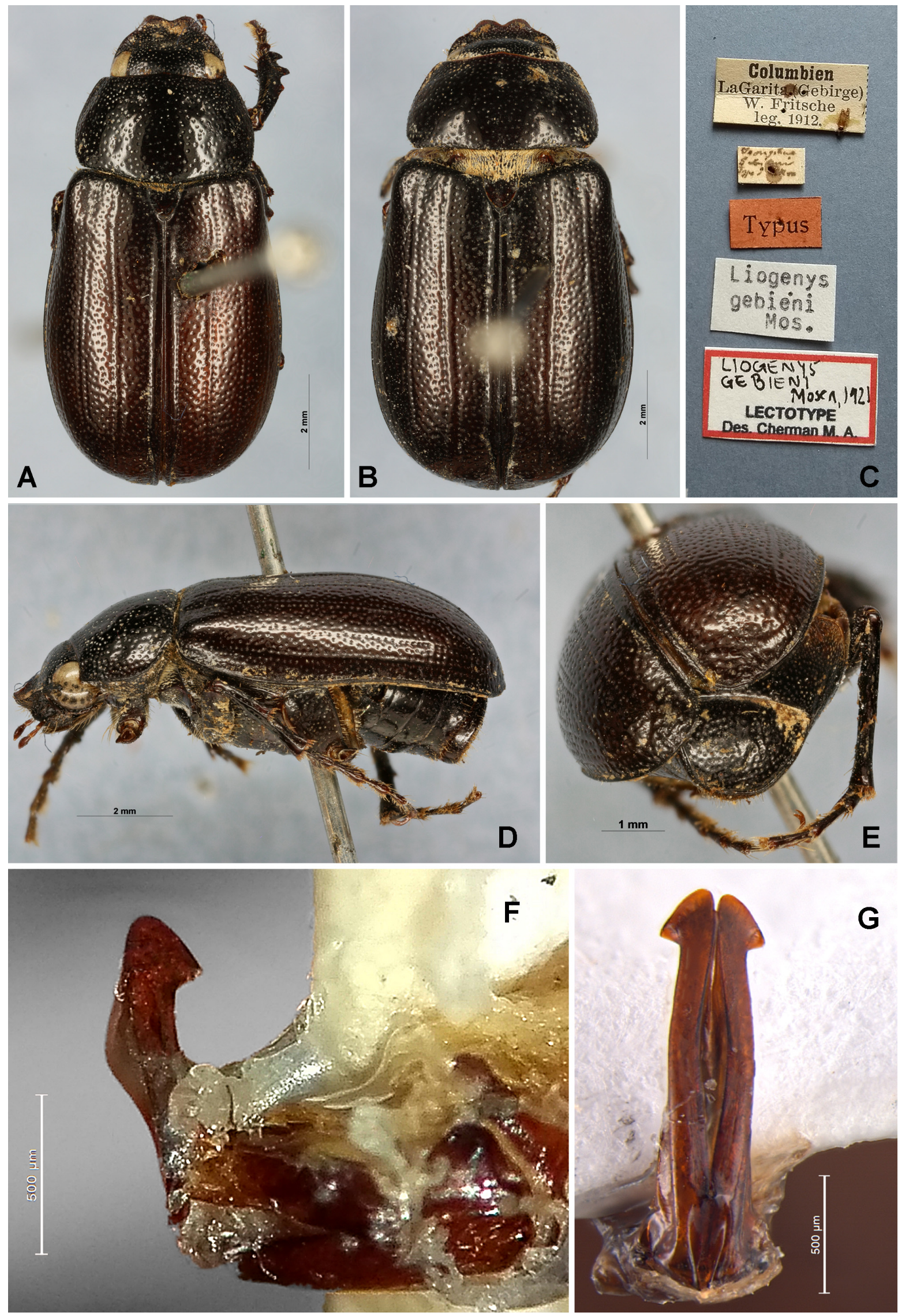

FIGURE 5. Liogenys gebieni Moser, 1921 lectotype views: A) dorsal, B) dorsal of female paralectotype, C) labels, D) lateral, E) pygidium, and dorsal view of F) one paramere compared with G) parameres of the Liogenys macropelma Bates, 1887 lectotype. 
Remarks. After studying the type series of L. gebieni (ZMHB) (Fig. 5A-C), and comparing its external features and male genitalia (Fig. 5A-F) with that of L. macropelma type series and non-type material (Fig. 5G), we concluded that these specimens belong to the same species. The only difference is the color, which is darker in the L. gebieni types. Nonetheless, the difference in body color is a common intraspecific variation within Liogenys. Herein, we propose L. gebieni Moser as a junior subjective synonym of L. macropelma Bates. The parameres of each L. macropelma and L. gebieni drawn by Frey (1969) seem to be different. However, there were no specimens labeled as L. gebieni among Frey's material housed at NHMB or USNM, thus, the material used by Frey (1969) to illustrate L. gebieni parameres remains unknown. According to the United States Department of Agriculture (1971, 1974), L. macropelma has been intercepted in Florida, Texas, and Puerto Rico (United States of America) coming by aircraft from El Salvador, Panama, and South America (probably Brazil) several times in a period from 1948-1971, always between April and May (identification verified based on the illustration in the report). Also, it was recorded being a host of okra plant Hibiscus esculentus L. (Malvaceae) coming from Guatemala, Panama, and Venezuela, which were intercepted in Florida, California, and Puerto Rico (United States of America). Several specimens in the USNM collection had been caught in port interceptions from Houston, Texas, originated from Panama, 1966 with no other explanation. Another specimen in the USNM bears the following data: 27 April 1962 port interception from Miami, Florida originating from "South America". Based on the poor state of taxonomy of the genus Liogenys when these port interceptions took place, all identifications should be considered questionable unless they can be verified using voucher specimens.

\section{Liogenys quadridens (Fabricius, 1798)}

Figs. 6, 9.

Melolontha quadridens Fabricius, 1798: 131 (original description).

Liogenys quadridens: Burmeister 1855: 14 (redescription); Harold 1869: 1140 (checklist); Bates 1887:155 (checklist); Dalla Torre 1913: 318 (checklist); Blackwelder 1944: 228 (checklist); Frey 1969: 50 (key); Evans 2003: 213 (checklist); Evans \& Smith 2009: 181-182 (checklist); Krajčík 2012: 145 (checklist); Cherman et al. 2017: 11, 16; 2019: 62 (taxonomy).

Type material examined. Melolontha quadridens female lectotype, present designation (ZMUC): [white handwritten] "4 Dens.", [white typeset] "zmuc / 00022369", [white, outlined in red, typeset and handwritten] "LIOGENYS / QUADRIDENS / (Fabricius, 1798) / LECTOTYPE / Des. Cherman M. A.”.

Additional material examined. PANAMA. Coclé: Río Hato, 22.V.1960, light trap, V.J. Tipton, 1 male, 1 female (CNCI). Panamá: Cerro Campana, 820 m, $8^{\circ} 40^{`}$ N, $79^{\circ} 56^{`}$ W, 22.V.1976, at blacklight, B.C. Ratcliffe, 2 males, 4 females (UNSM); Cerro Campana, 2600 feet, 10-20.V.1981, J.E. Wappes, 1 male, 1 female (UNSM). Panamá Oeste: Nueva Gorgona, 25.V.1962, R.\&F. Zweifel, 1 male, 1 female (AMNH); Sajalices, 17.V.1982, E. Giesbert, 1 male, 3 females (UNSM). Veraguas: Santiago, 18.V.1977, H. Howden, 1 male (CMNC). VENEZUELA. Guárico: San Juan de Los Morros, 28.IV.1938, C.H. Ballou, 1 female (USNM); Monagas: El Tejero, 200 m, 2.V.1964, C. Bordon, 1 male (CMNC). Distrito Capital: Caracas, 1938, G. Vivas-R., 2 males (USNM). Without locality and date, E. Kummerow S., 1 female (ZMHB).

Diagnosis. Body light brown, elongate, males with sides parallel (Fig. 6A), females with sides slightly wider on posterior third (Fig. 6B); elytra light brown to yellowish brown, pronotum reddish to purplish brown, head even darker; clypeus quadridentate; clypeal emargination deep, rounded, and wide (Fig. 1A), slightly narrower in females than in males (Fig. 1B); distance between lateral and anterior clypeal teeth longer than basal width of one anterior tooth; angle between lateral and anterior clypeal teeth approximately $90^{\circ}$; mesotibia subquadrate in cross section; pygidium flat or slightly convex, pygidial disc glabrous, with scattered bristles on apex (Fig. 6D); males with protarsomere II less than twice the length of protarsomere I in dorsal view; parameres elongate, up to three times the length of their apex (Fig. 6H), inner margins straight, lateral expansion on outer margins along the parameres partially hidden in dorsal view (Fig. 1E), apex harpoon-shaped, lateral spine projected backwards, slightly convergent to the outer margin of the parameres; spine length slightly more than twice the length of the apex, subapical and proximal part of the apex elevated medially (Fig. 6), abruptly flattened distally at apex and spine (Fig. 6G).

Redescription. Length: 9.2-10.8 mm, width: 4.6-5.0 mm. Light brown to brown. Head: dark, distance between eyes nearly twice the width of one eye; frons equal in length to clypeus; clypeal emargination deep, rounded, and narrow; outer sides of anterior teeth parallel; outer margin of anterior teeth shorter than the eye in dorsal view; 
clypeus convex laterally and strongly produced forming a conspicuous, tooth-like projection; distance between lateral and anterior teeth longer than basal width of one anterior tooth, distance between lateral tooth and anterior margin of eye longer than one eye length, angle between anterior and lateral teeth approximately $90^{\circ}$; canthus exceeding or not the outer margin of the eye; distal maxillary palpomere maximum width twice the width at apex; fovea deep, extending past the transverse midline of the palpomere; antenna with 10 antennomeres, club lighter in color, as long as the funicle in females, longer than the funicle in males. Thorax: pronotal anterior margin slightly produced medially, undulate; disc glabrous, punctures sparse and fine in females, coarser in males; pronotal posterior corners rounded in males, apparently obsolete in females; hypomere with long bristles; mesepisternum scaly; anterior portion and sides of metaventrite with bristles; distance between mesocoxae and metacoxae nearly twice the length of the metacoxa; scutellum triangular, punctures mainly at the sides. Elytra: shiny, uniform yellowish brown to light brown, lighter in color than pronotum; elytra near three times longer than the pronotum; elytral suture slightly darker than elytron and not elevated; all four elytral ridges weakly defined. Legs: procoxa with long bristles on infra-carinal surface and fine scales and short bristles on outer surface; three protibial teeth, middle and apical equal in size, distance between basal and middle teeth longer than between middle and apical; protibial spur present; mesofemur with a row of long bristles on anterior and posterior margins, mesotibia quadrate in cross section, surface coarsely sculptured in females, finely sculptured in males, mesotibia with two transverse carinae, the apical carina complete in females, incomplete in males; metacoxa with bristles throughout and forming a row of scales parallel to the anterior margin (Fig. 6F); basal articular lobe of metacoxa produced beyond the outer margin of trochanter; inner margin of male metatibia carinate and produced on apex, apical inner surface with scattered bristles, metatibial disc coarsely sculptured; metatibial transverse carina and discontinuous longitudinal carina present posteriorly; metatarsomere I and metatarsomere II equal in length; males with protarsomere II as wide as it is long; protarsomeres and mesotarsomeres I-IV equally enlarged, wider than metatarsi; claw bifid, symmetrical, outer tooth of a claw longer and narrower than inner tooth; distance between teeth shorter than the inner tooth. Abdomen: disc of ventrites with sparse bristles; propygidium with bristles, pygidium flat, subtrapezoidal, wide, pygidial width exceeding distance between spiracles of propygidium; pygidial disc glabrous, few bristles on apex, coarsely punctate, roughly in males; slightly depressed medially in males; pygidial apex quadrate. Parameres: basal region slightly wider than both sections of the parameres at its midline; parameral split at $2 / 3$ the length of the basal region; parameres almost three times the length of their apex; inner margins straight; lateral expansion of the outer margins partially hidden, visible from the midline up to the subapical portion; apex harpoon-shaped, lateral spine straight backwards, slightly bent, spine length more than twice the length of the apex, subapical and proximal part of the apex elevated medially, flattened distally at apex and spine (Figs. 1E, 6G). Parameres concave in lateral view (Fig. 6E).

Type locality. "India Orientali" [Burmeister 1855: 14, misinterpreted locality of West Indies]. Species from Panama and Venezuela.

Geographic distribution. PANAMA (Coclé, Panamá, Panamá Oeste, Veraguas), VENEZUELA (Distrito Capital, Monagas).

Remarks. Liogenys quadridens was redescribed for the first time by Burmeister (1855), who transferred it from Melolontha Fabricius, 1775 to Liogenys. Fabricius (1798) mentioned in the original description that the species is from "India Orientali" [East Indies], we interpreted that he meant West Indies instead. According to Burmeister (1855) and Harold (1869), L. quadridens occurs in Colombia and Guyana. Bates (1887) stated that this species occurs in "Amazons" but this record should be disregarded as it was surely based on the misidentification of other species of Liogenys. Bates (1887) also cited Panama, "Volcán de Chiriqui 2500 to 4000 feet (Champion)" but these specimens are here identified as L. quadridentata (based on our examination of these specimens in the BMNH). Frey (1969) cited the distributional limits of this species, from Florida (United States of America) (presumably based on port interception specimens) to Pernambuco (Brazil). In his key, Frey (1969) mentioned an intraspecific variation in the pronotal punctures and in the shape of the parameres, which he drew. At NHMB, we found the specimen from Pernambuco and it is here identified as L. piauiensis Cherman, 2017. Therefore, we refute the occurrence of $L$. quadridens in Brazil. Among the 41 specimens studied from seven collections bearing L. quadridens identification, we found one male from Nueva Gorgona (Panama) matching with the parameres drawn by Frey (1969), and a female of the same collection event which matches with L. quadridens lectotype.

Liogenys quadridens has been cited by the United States Department of Agriculture $(1969,1971,1974)$ in its list of intercepted plant pests, carried by aircraft, in unknown hosts. The first time cited (1967-1968) it was 

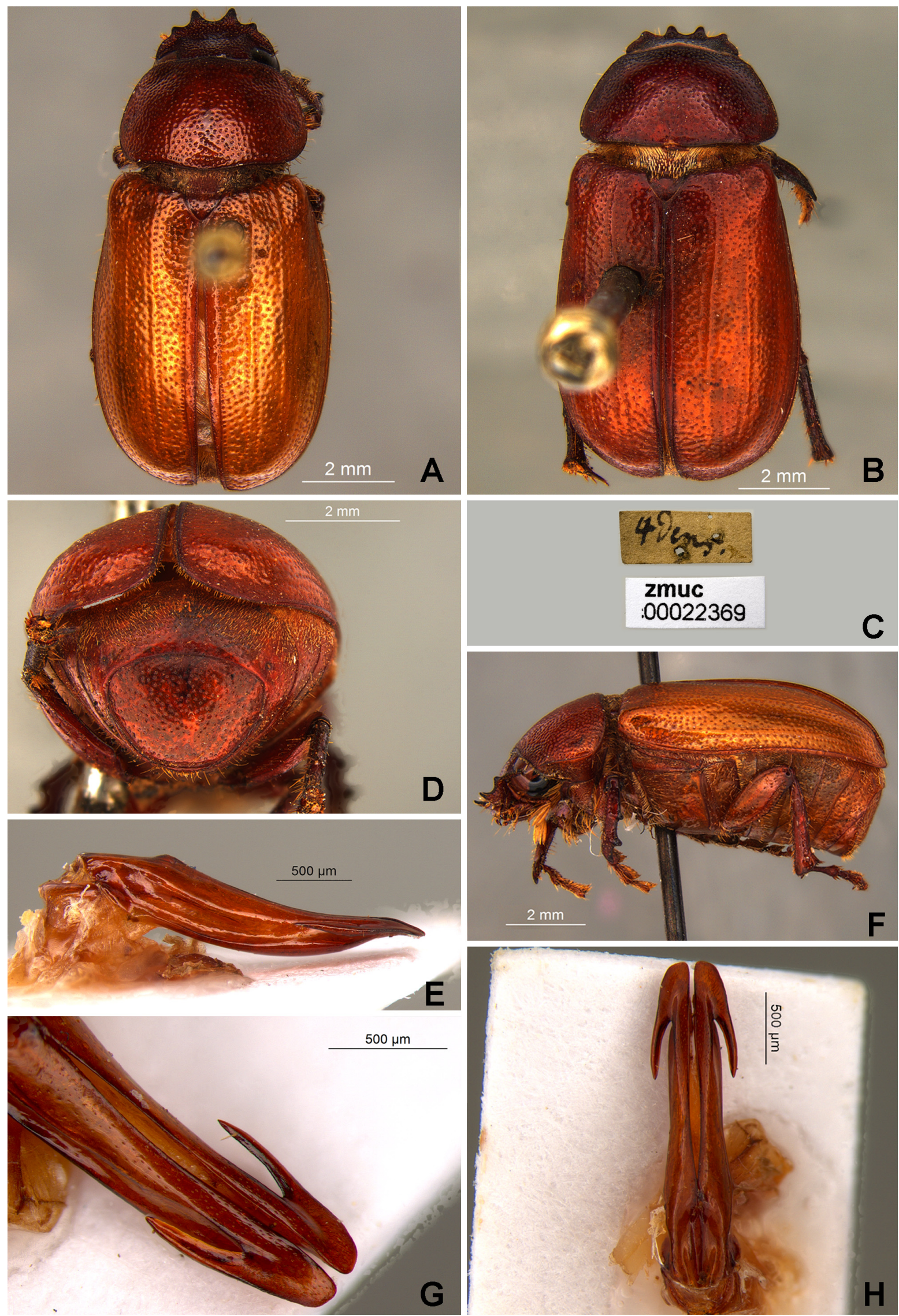

FIGURE 6. Liogenys quadridens (Fabricius, 1798) male views: A) dorsal, B) female lectotype, and C) labels, D) pygidium, E) lateral, and parameres F) lateral, G) dorsolateral of apex, H) dorsal. 
being carried from Panama, and the following (1971-1972) probably from Venezuela (United States Department of Agriculture 1969, 1974). This species was also cited as a tomato plant host from Maracaibo, Venezuela (MoralesValles et al. 2003), and there exists reports of this species in imported ripe tomato fruit throughout the European and Mediterranean Plant Protection Organization (EPPO) region. Nonetheless, as it is not likely to be transported in tomatoes it is classified non dangerous (Grousset et al. 2015). In a study on scarab beetles abundance of a tropical dry forest in Colombia, García-Atencia et al. (2015) found that L. quadridens was the most abundant species (1,667 individuals), characterized as an important pest of semestral crops in the Colombian Caribbean. After studying several specimens of the Caribbean region we cannot confirm that all those specimens mentioned on the previous works are L. quadridens. Although we do believe that L. quadridens occurs in Colombia (based on the known distribution in Panama and Venezuela), we did not examine any specimens to confirm this country record.

\section{Liogenys quadridentata Blanchard, 1851}

Figs. 7, 9.

Liogenys quadridentatus Blanchard, 1851: 168 (original description); Lacordaire 1855: 269 (checklist); Harold 1869:1140 (checklist); Dalla Torre 1913: 318 (checklist); Krajčík 2012: 145 (checklist).

Liogenys quadridentata: Blackwelder 1944: 228 (checklist); Evans 2003: 213 (checklist); Evans \& Smith 2009: 182 (checklist).

Amphicrania 4-dentata [quadridentata] Klug in litt. Burmeister 1855: 14 (synonym of Liogenys quadridens, nomen nudum). Amphicrania quadridentatus Klug in litt.: Harold 1869: 1140 (synonym of L. quadridens).

Type material examined. Liogenys quadridentatus male lectotype, present designation (MNHN): [white handwritten] "292 / 39", [green handwritten] "Amphicrania / 4 Dentata.", [light green typeset] "MUSEUM PARIS", [green handwritten] "L. quadridentatus / Cat Mus", [red typeset] "HOLOTYPE", [white, outlined in red, typeset and handwritten] "LIOGENYS / QUADRIDENTATA / Blanchard, 1851/ LECTOTYPE / Des. Cherman M. A.", genitalia mounted.

Additional material examined. PANAMA. Chiriquí: Volcán de Chiriquí, 2500-4000 feet, G.C. Champion, 4 males (BMNH). Panamá: La Chorrera, 2 females (BMNH). COLOMBIA. Magdalena: 12 miles W Santa Marta, 28.IV.1973, J.M. Campbell \& H.F. Howden, 1 female (CMNC); 12 miles W Santa Marta, 29.IV.1973, J.M. Campbell \& H.F. Howden, 1 male, 3 females (CMNC); 12 miles W Santa Marta, 12.V.1973, J.M. Campbell \& H.F. Howden, 2 males (CMNC); 18.V.1973, 3 males, 5 females (CMNC); Parque Tayrona, 21 miles E Santa Marta, 15.V.1973, H.F. Howden \& J.M. Campbell, 1 female (CMNC); Aracataca, 25.III.28, Darlington, 1 female (AMNH); Santa Marta, 3.V.1928, Darlington, 1 male (AMNH); Bonda, VI, 12 females (CMNH). VENEZUELA. Delta Amacuro: 15 km E Los Casillos, 45 km NE Ciudad Guyana, 26.VI.1985, ultraviolet light, M.A. Ivie, 3 females (CMNC). Guárico: 12 km W Valle de la Pascua, 21-22.VI.1996, light, H.\&A. Howden, 1 female (CMNC); Estación Biológica Los Llanos, 12 km S Calabozo, 6-12.II.1969, ultraviolet light, P.\&P. Spangler, 16 males, 9 females (USNM). Sucre: Cariaco, 20.V.1959, C. Bordon, 1 female (CMNC). Zulia: Maracaibo, without date, E. v. Jess., 1 male (ZMHB). Without locality and date, Moequerys, 2 females (SDEI); with erroneous locality (Brazil), without date, Mniszech, 1 female (MNHN).

Diagnosis. Body light brown, elongate, sides parallel in males (Fig. 7A), slightly wider on posterior third in females; elytra light brown to yellowish brown, pronotum reddish to purplish brown; clypeus quadridentate; clypeal emargination deep, rounded, and narrow (Fig. 1C); anterior margin noticeable bent upwards, especially in females (Fig. 1D); distance between lateral and anterior clypeal teeth as long as basal width of one anterior tooth; acute angle between lateral and anterior clypeal teeth; mesotibia cylindrical in cross section (Fig. 7D); pygidium convex in both sexes, females with pygidium strongly convex medially (Fig. 7E); pygidial disc glabrous, with scattered bristles on apex; males with protarsomere II more than twice the length of protarsomere I in dorsal view; parameres up to three times the length of their apex (Fig. 7F); inner margins opened, slightly convergent; apex harpoon-shaped, lateral spine projected backwards, almost parallel to the outer margin of the parameres; spine length slightly more than twice the length of apex, subapical and part of the apex elevated medially, abruptly flattened at apex and spine.

Redescription. Length: 9.4-11.2 mm, width: 4.7-5.2 mm. Brown. Head: distance between eyes nearly twice the width of one eye; frons somewhat swollen; clypeal emargination deep, rounded, and narrow; outer sides of anterior teeth parallel; outer margin of anterior teeth shorter than the eye in dorsal view; clypeus convex laterally and strongly produced forming a conspicuous tooth-like projection; in females anterior margin noticeable bent upwards; 
distance between lateral and anterior teeth equal to basal width of one anterior tooth, distance between lateral tooth and anterior margin of eye longer than one eye length, acute angle between anterior and lateral teeth; distal maxillary palpomere maximum width wider than at apex; fovea deep, extending up to the transverse midline of the palpomere; antenna with 10 antennomeres, club lighter in color and longer than funicle. Thorax: pronotal anterior margin slightly produced medially; punctures very sparse, denser and coarser than the disc towards anterior margin; pronotal posterior corners rounded; hypomere with long bristles; mesepisternum with sparse, thin scales; anterior portion and sides of metaventrite with bristles; distance between mesocoxae and metacoxae nearly twice as long as metacoxal width; scutellum triangular, sparse punctures at the base and sides. Elytra: shiny, uniform light brown or yellowish brown, lighter in color than the pronotum; elytral suture unicolored with elytron and slightly elevated or flat; all four elytral ridges weakly defined. Legs: procoxa with bristles, fine, thin scales on outer surface; three protibial teeth, middle and apical teeth equal in size, distance between basal and middle teeth longer than between middle and apical teeth; protibial spur present; mesotibia cylindrical in cross section, surface finely sculptured, mesotibia with two transverse carinae, the apical carina incomplete in males, complete in females; metacoxa with bristles throughout; inner margin of male metatibia carinate and produced straight towards apex, apical inner surface glabrous, metatibial disc coarsely sculptured along the outer margin; metatibial transverse carina present posteriorly; protarsomere II elongate; protarsomeres and mesotarsomeres I-IV enlarged, protarsomeres slightly wider than the mesotarsomeres, more than twice the width of metatarsomeres; metatarsomere I slightly shorter and wider than metatarsomere II; claw bifid, outer tooth of a claw equal in length and narrower than the inner tooth; distance between teeth shorter than the inner tooth. Abdomen: disc of ventrites with sparse bristles; propygidium with bristles, pygidium convex, convexity with intraspecific variation, females with pygidium inflated medially; pygidium subtrapezoidal, apex rounded; pygidial maximum width exceeding the distance between spiracles of propygidium; pygidial disc glabrous, few bristles on apex. Parameres: basal region narrowed at the midline; parameral split at 2/3 the length of the basal region; length of parameres nearly three times the length of their apex; inner margins convergent; apex harpoon-shaped, lateral spine projected backwards, slightly divergent from the outer margin of the parameres, spine length slightly more than twice as long as apex, subapical and proximal part of the apex elevated medially, abruptly flattened distally at apex towards the spine. Parameres concave, not coplanar in lateral view (Fig. 7G).

Type locality. Not established.

Geographic distribution. COLOMBIA (Magdalena), PANAMA (Chiriquí), VENEZUELA (Delta Amacuro, Guárico, Sucre, Zulia).

Remarks. The lectotype of Liogenys quadridentata bears a green label "Amphicrania 4-dentata", a name credited to "Klug MSC" by Burmeister (1855) but not formally validated until Blanchard (1851) described the species. Burmeister (1855) listed the name as a junior synonym of L. quadridens. Soon after, Harold (1869) mentioned "Amphicrania 4-dentata" as a synonym of L. quadridens, followed by "in litt.", which means: "new species mentioned in litteris (in correspondence), that will be described later in a separate paper". Harold (1869) probably did not see the L. quadridentata type series, so he did not associate the name "Amphicrania 4-dentata" to the latter. After the mentioned synonymy of "Amphicrania 4-dentata" (Burmeister 1855; Harold 1869), L. quadridentata was suggested to be a junior synonym of L. quadridens by later authors (Bates 1887; Dalla Torre 1913). We here confirm that L. quadridentata is a different species from L. quadridens. Liogenys quadridentata differs from L. quadridens (in parenthesis) mainly in the anterior margin of clypeus strongly bent upwards (not strongly bent); anterior and lateral tooth closer and acute angle between them (anterior and lateral tooth less close and right angle between them); mesotibia cylindrical in cross section (mesotibia subquadrate); pygidium noticeably convex, inflated medially in females (pygidium flat in both sexes); males with the protarsomere II longer (as wide as it is long), and the parameres are different in shape.

The lectotype of L. quadridentata does not bear any locality data, and Blanchard (1851) did not mention the type locality in the original description. This fact agrees with Lacordaire (1855), who described the locality of $L$. quadridentata as "Patrie inconnue". However, Burmeister (1855) and then Harold (1869) mentioned "Columbia" [current Colombia and Panama] as a locality record of "Amphicrania 4-dentata", which is likely the actual distribution of this species. Dalla Torre (1913) cited L. quadridentata from Montevideo (Uruguay). This is here interpreted as an error, which was reproduced by Blackwelder (1944) and subsequent authors. Due to the layout of Blanchard (1851) descriptions when they are contiguous, it is easy to attribute the type locality of one species to the next one. It is most likely that Dalla Torre (1913) attributed the type locality of Liogenys parva Blanchard, 1851 to L. quadridentata. 

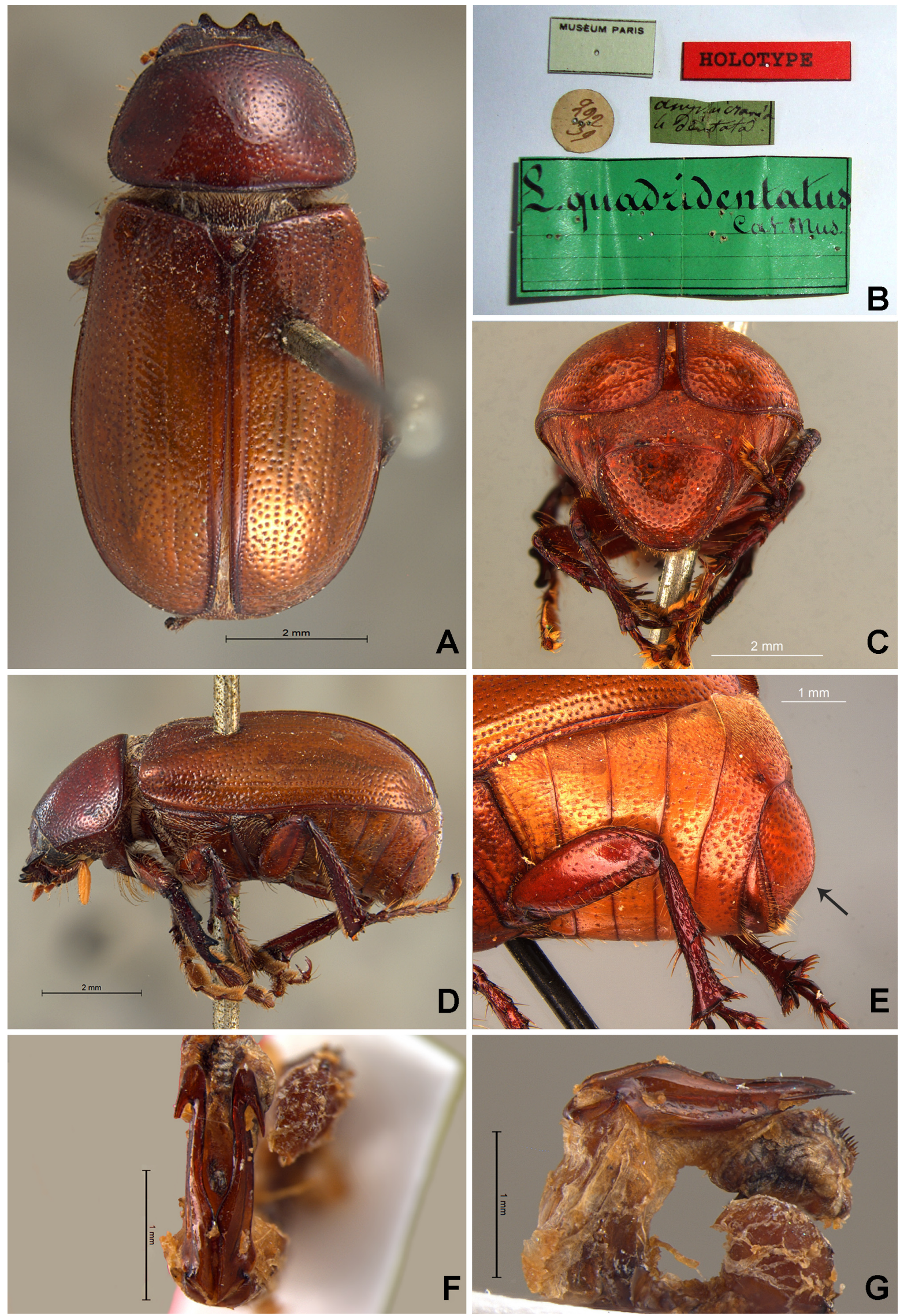

FIGURE 7. Liogenys quadridentata Blanchard, 1851 male lectotype views: A) dorsal, B) labels, C) pygidium, D) lateral, E) lateral of pygidium in females, and parameres F) dorsal and G) lateral. Black arrow indicates the E) inflated pygidium of females. 

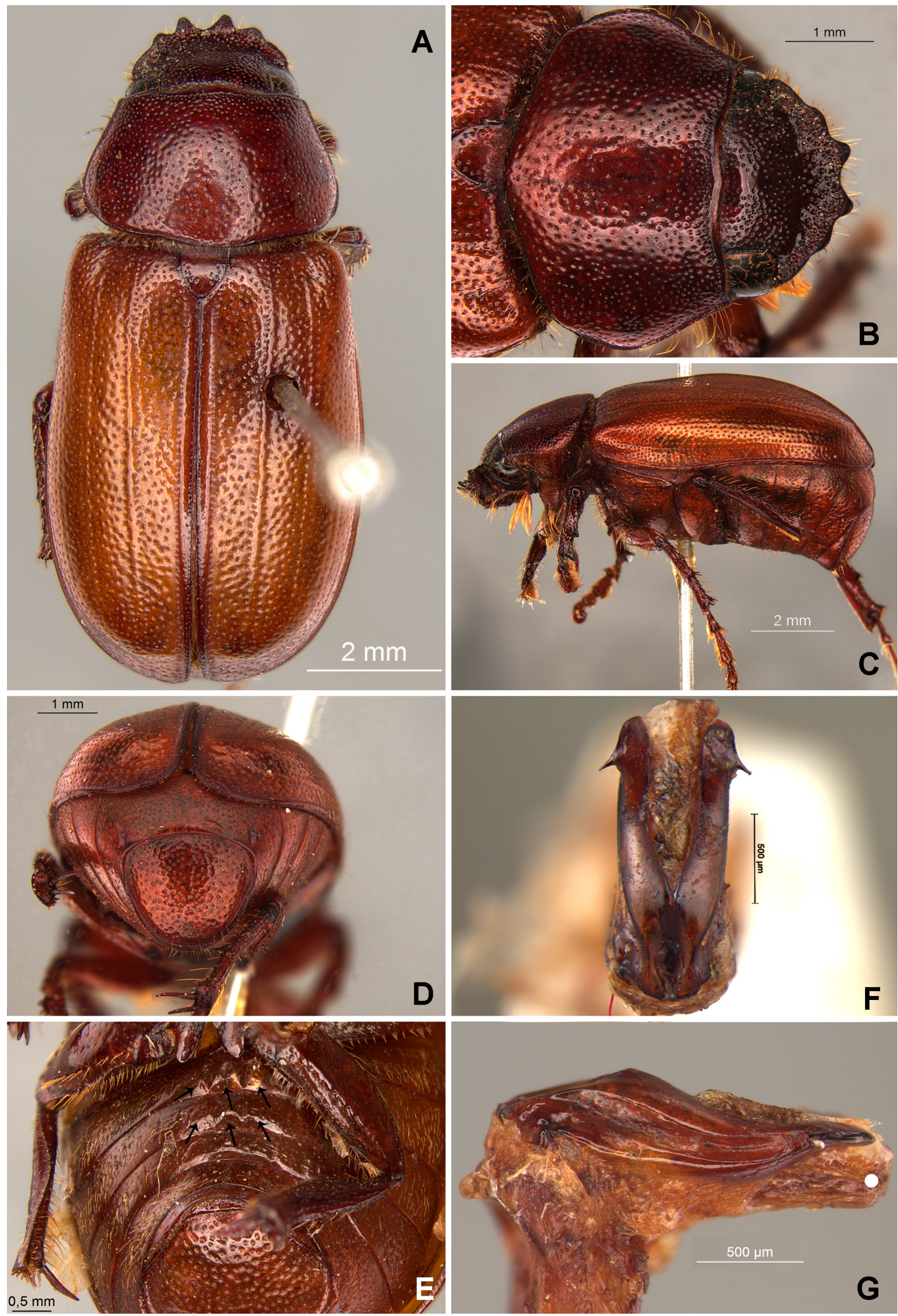

FIGURE 8. Liogenys schneiderae Cherman new species male holotype views: A) dorsal, B) clypeus and pronotum, C) lateral, D) pygidium, E) ventral of abdomen, black arrows indicate the tubercles at ventrites II-III, and parameres F) dorsal and G) lateral. 


\section{Liogenys schneiderae Cherman, new species}

Figs. 8, 9.

Type material. Holotype male, labeled: [green, handwritten] "4-dens Fbr / 4-dentata / kl. / Pg.[?] / Col. [Colombia]", [white, typeset and handwritten] "MLU Halle / WB Zoologie / S. -Nr. 8/3/11", [red typeset and handwritten] "LIOGENYS / SCHNEIDERAE / HOLOTYPE / Cherman M. A." (MLUH). Paratypes (81), all bearing the label [yellow, typeset and handwritten] "LIOGENYS / SCHNEIDERAE / PARATYPE / Cherman M. A.". One female with the labels: [white handwritten] "Venezuela", [white typeset and handwritten] "Liogenys quadri- / dens / F det. G. Frey, 1968" (ZMHB). One female with the label: [green typeset] "Venezuela /F. Kummerow S." (ZMHB). Two females and one male with the following label: [white handwritten] "Guyana" (ZMHB). Two females and two males with the label: [green, outlined, typeset] "Hist. Coll. (Coleoptera) / Nr. 24131 / Liogenys quadridens Burm. / Columb., Moritz. / Zool. Mus. Berlin" (ZMHB). One male with the labels: [white typeset] "24131", [dark green handwritten] "Amphicrania / 4 dentata Nr / Columb. Moritz", [white handwritten] "quadridens / Burm / Melol. 4 dens Fab." (ZMHB). Two males bearing the labels: [white handwritten] "Colombia / Mus. Ber. / 4-dentata / Kl.", [white typeset] "Mus. Western" (ZMUC). One male bearing: [white typeset] "Coll. Kraatz", [white typeset] "Moser det", [white typeset] "Dtsch. Ent. Inst. / Eberswalde", [white outlined green, handwritten] "quadridens. / Guyana /F.", [white handwritten] "Liogenys. /Guerin.", [white handwritten] "Liogenys / quadridens Fab", [white, typeset and handwritten] "Liogenys quadri- / dens / F det. G. Frey, 1968", [white handwritten] "Liogenys/quadridens / F.", [light green typeset] "DEI Münchenberg / Col - 03566" (SDEI). One male with the following data: [white typeset] "CARIACO / (Edo. SUCRE)", [white typeset] "Bordon leg." / [handwritten] "10-IV-59" [white handwritten] "4", [white, outlined, typeset] "H. \& A. HOWDEN/COLLECTION / ex. A. Martinez coll." (CMNC). One female with the data: [white typeset] "QUIAMARE[Libertad] / (BARCELONA)", [white typeset] "5-4-58/BORDON LEG.", [white, outlined, typeset] "H. \& A. HOWDEN / COLLECTION / ex. A. Martinez coll." (CMNC). Two females with the data: [white, typeset] "Aragua / Venezuela / V.1978" (USNM). One male with the data: [white, typeset] "Chaguarramas / (Edo. Guarico)", [white typeset] "13-3-60 / BORDON LEG.", [white, handwritten and typeset] "Liogenys quadridens $\hat{\sigma} /$ (Fab.) / A MARTINEZ-DET. 1974", [white with black border, typeset] "H. \& A. HOWDEN / COLLECTION / ex. A. Martinez coll.", genitalia mounted (CMNC). Two males and four females with the data: [white, typeset] "West Indies: / Tobago: / Scarborough. / 16. vi. 1914. / W.E. Broadway." and "Brit. Mus. / 1920-487." (1 male and 2 females at BMNH; 1 male and 2 females at CMNC). One male with the data: [white, typeset] "West Indies: / Tobago: / Scarborough. / 17. vi. 1914. / W.E. Broadway." and "Brit. Mus. / 1920-487." (BMNH). One female with the data: [white, typeset] "West Indies: / Tobago: / Scarborough. / 10. vi. 1914. / W.E. Broadway." and "Brit. Mus. / 1920-487." (BMNH). One female with the data: [white, typeset] "West Indies: / Tobago: / Scarborough. / 12. vi. 1914. / W.E. Broadway." and "Brit. Mus. / 1920-487." (BMNH). Two females with the data: [white, typeset] "West Indies: / Tobago: / Scarborough. / 15. vi. 1914. / W.E. Broadway." and "Brit. Mus. / 1920-487." (BMNH). Two females with the data: [white, typeset] "West Indies: / Tobago: / 9. vi. 1914. / W.E. Broadway." and "Brit. Mus. / 1920-487." (BMNH). One male with the data: [white, handwritten] "quadridens / Fabr. / 4-dentata, / Klug. / Columbia", [white, typeset] "So named / in Reiches / Collection. / C.W.", [green, handwritten] “ ’”, [white, handwritten] "nov. sp.", [light blue, handwritten] "2258.", [white, typeset] "67.45" (BMNH). Sixteen males and 15 females with the data: [white, typeset] "VENEZUELA: Guarico, Hato / Masaguaral, 45kmS Calabozo / 8.57N,67.58W, GalryForest / \#28, 75m, 3-5 June 1988 / uv light, M. Epstein" (eight males and eight females at USNM, four males and three females at CMNC, two males and two females at DZUP, two males and two females at CEMT). Paratypes of DZUP with the sequence of voucher numbers: [white typeset] "DZUP / 402753" to "DZUP / 402756". One male and eight females with the data: [white, typeset] "VENEZUELA: Guarico, Hato / Flores Morades, 45 km S / Calabozo, 8.57N, 67.58W / Galry Forest \#2, 75 m / 24-26June 1989, uv light / M. Epstein \& M. Rodiguez" (USNM). One male and two females with the data: [white, typeset and handwritten] "ex ? / intercepted / at Miami Fla / 1 May 1964" (USNM). One male and two females with the data: [white, typeset and handwritten] "VENEZUELA: BOLIVAR / Guri, 16.VI.1996 / H.\&A. Howden Lt / Wet forest" (CMNC). One female with the data: [white, typeset and handwritten] "VENEZUELA: GUARICO / 12km W Valle de la / Pascua, 21-22.VI.96 Lt / H.\&A. Howden" (CMNC). One female with the data: [white, typeset] "VEN: Bolivar, 20km / SW Ciudad Bolivar / 19. VI. 1987, S\&JPeck / woodland on sand, UV" (CMNC). One female with the data: [white, typeset] "VENEZ: Anzoategui / 18 km E Pariaguan / 24JUN1987, 240m / M.A. Ivie, beating” (CMNC). 

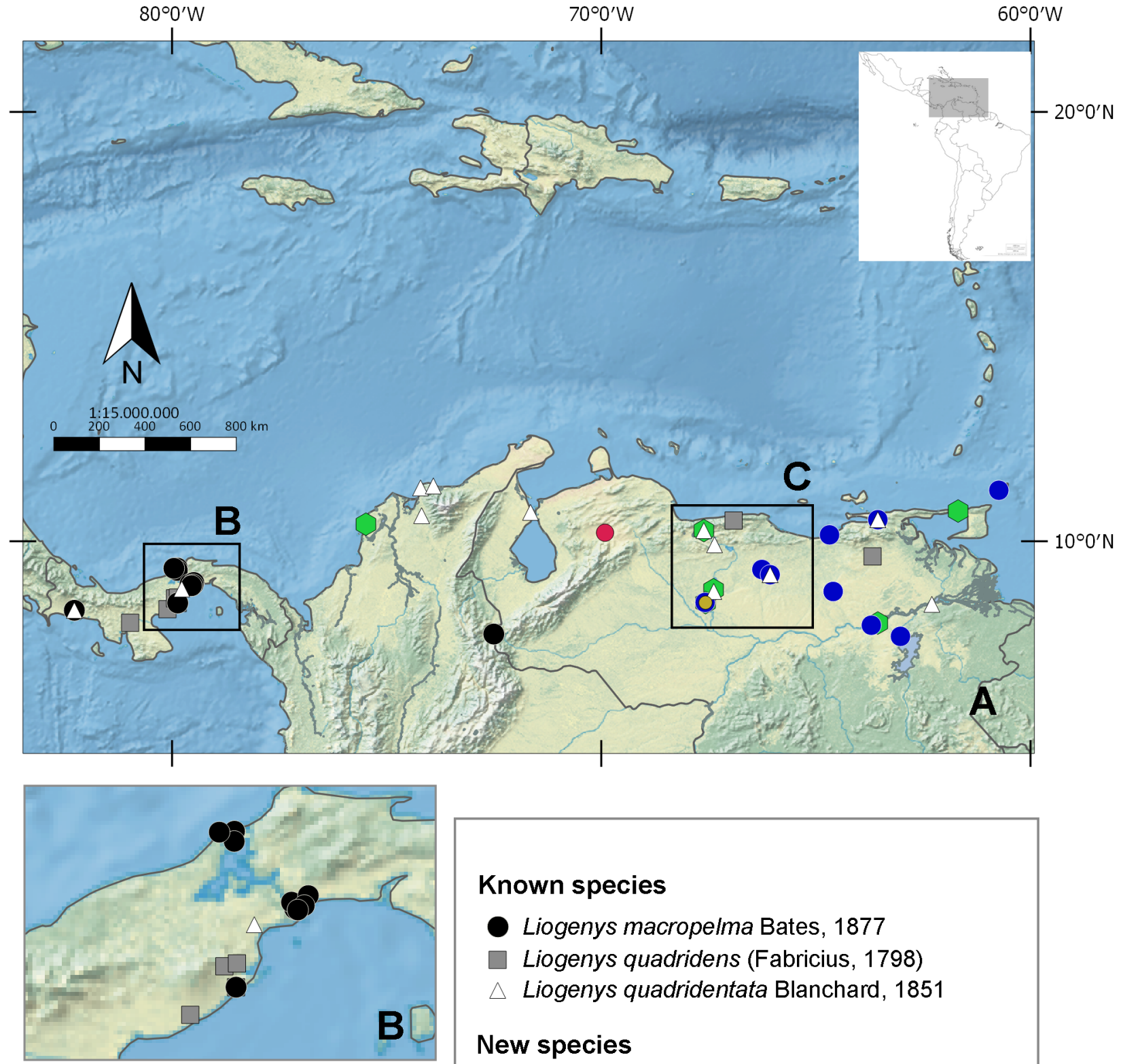

\section{Known species}

Liogenys macropelma Bates, 1877

Liogenys quadridens (Fabricius, 1798)

$\triangle$ Liogenys quadridentata Blanchard, 1851

New species

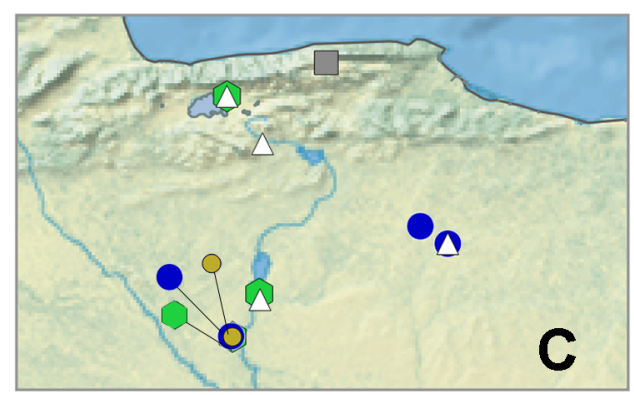

- Liogenys genieri Smith \& Cherman new species

- Liogenys clipeosetosa Cherman new species

- Liogenys schneiderae Cherman new species

Liogenys granadina Cherman new species

FIGURE 9. Geographical distribution of the Liogenys of A) the northern South America and Central America, overlapping records in B) Panama and in C) Venezuela.

Holotype deposited at MLUH. Eleven paratypes at BMNH. Nineteen paratypes deposited at CMNC. Four paratypes at DZUP, four paratypes at CEMT. One paratype deposited at SDEI. Thirty paratypes deposited at USNM. Ten paratypes deposited at ZMHB. Two paratypes deposited at ZMUC.

Additional material. One male (BMNH) missing the head and pronotum with the data: [white, typeset and handwritten] "Scarborough, / Tobago. / 15 May 1914. / W.E. Broadway. / 1914-403". 
Diagnosis. Body brown, elongate, sides almost parallel in males (Fig. 8A), slightly wider on posterior third in females; elytra brown; pronotum reddish to purplish brown; clypeus quadridentate, clypeal emargination deep, rounded, and narrow; distance between lateral and anterior clypeal teeth slightly longer than basal width of one anterior tooth; right angle between lateral and anterior clypeal teeth; pronotal corners rounded (Fig. 8B), appearing obsolete especially in females; mesotibia quadrate in cross section (Fig. 8C); pygidium weakly convex; pygidial disc glabrous, with scattered bristles on apex (Fig. 8D); ventrites II, III, and sometimes IV undulate on midline, especially ventrite II (Fig. 8E); in males protarsomere II up to twice the length of protarsomere I in dorsal view; metatibia subbasally produced towards apex; basal region of parameres strongly narrowed, parameres more than five times the length of their apex; apex harpoon-shaped, lateral spine short, projected almost perpendicular to parameres (Fig. 8F).

Holotype. Male. Length: $9.4 \mathrm{~mm}$, width: $4.4 \mathrm{~mm}$. Brown. Head: distance between eyes nearly twice the width of one eye; frons longer than clypeus; clypeus rugose, clypeal emargination deep, rounded, and narrow; outer sides of anterior teeth parallel; outer margin of anterior teeth shorter than the eye in dorsal view; clypeus convex laterally and strongly produced forming a conspicuous tooth-like projection; distance between lateral and anterior teeth slightly longer than basal width of one anterior tooth, distance between lateral tooth and anterior margin of eye longer than one eye length, angle between anterior and lateral teeth approximately $90^{\circ}$; canthus not exceeding the outer margin of the eye; distal maxillary palpomere maximum width slightly wider than at apex; fovea shallow, extending past the transverse midline of the palpomere; antenna with 10 antennomeres, club lighter in color and as long as the funicle. Thorax: pronotal anterior margin slightly produced medially, undulate and flanged (Fig. 8B); maximum length of pronotum exceeding the length of tarsomeres I-III combined; disc glabrous, punctures very sparse and coarse, denser towards anterior margin; pronotal posterior corners rounded, appearing obsolete; hypomere with long bristles and thin scales; mesepisternum scaly; anterior portion and sides of metaventrite with bristles; distance between mesocoxae and metacoxae nearly twice the length of the metacoxa; scutellum triangular, few, scattered, fine punctures at the sides. Elytra: shiny, uniform light brown, lighter in color than the pronotum; elytra more than three times longer than the pronotum; elytral suture darker than the elytron and slightly elevated; all four elytral ridges weakly defined. Legs: procoxa scaly, thin scales on outer surface; three protibial teeth, middle and apical teeth equal in size, distance between basal and middle teeth longer than between middle and apical teeth; protibial spur present; mesofemur with a row of long bristles on anterior and posterior margins, mesotibia subquadrate in cross section, surface finely sculptured, mesotibia with two transverse carinae, the apical carina incomplete; metacoxa with bristles throughout, basal articular lobe of metacoxa produced beyond the outer margin of trochanter; inner margin of metatibia carinate and abruptly subbasally produced towards apex, apical inner surface glabrous, metatibial surface coarsely sculptured on outer margin; metatibial transverse carina present posteriorly; protarsomere II very elongate; protarsomeres and mesotarsomeres I-IV enlarged, protarsomeres equal in width to the mesotarsomeres, slightly wider than the metatarsomeres; metatarsomere I shorter than metatarsomere II; claw bifid, outer tooth of a claw longer and narrower than the inner tooth; distance between teeth shorter than the inner tooth. Abdomen: disc of ventrites with sparse bristles; ventrites II-III and sometimes IV with tubercles on disc (Fig. 8E); propygidium with bristles, pygidium slightly convex, subtrapezoidal, wide; pygidial width exceeding distance between spiracles of propygidium; pygidial disc glabrous, few bristles on apex, pygidial disc finely punctate; pygidial apex quadrate. Parameres: basal region dorsally narrowed, narrower than both sections of the parameres at its midline; parameral split at 2/3 the length of the basal region; parameres more than five times the length of their apex; inner margins opened, convergent; apex harpoon-shaped, lateral spine thin, short, projected almost perpendicular to parameres (approximately $80^{\circ}$ angle). Parameres concave in lateral view (Fig. 8G).

Variation. Female length: 9.2-10.2 mm, width 4.5-5.3 $\mathrm{mm}$. females as the holotype except the clypeal anterior teeth wider; canthus exceeding the outer margin of the eye; pronotal corners more marked; metatibia coarsely sculptured, metatibial apical carina complete; ventrite tubercles more noticeable and pygidium wider, more trapezoidal. Male length: $9.0-9.5 \mathrm{~mm}$, width $4.4-4.8 \mathrm{~mm}$. Males as the holotype except the head and pronotal punctures coarser; pronotal corners more marked, and pygidium flatter and bent downwards.

Etymology. The species is dedicated to Dr. Karla Schneider, biologist and curator of the Zoological Collection of the Martin-Luther-Universität, Halle-Wittenberg, Halle, Germany. Karla made the discovery of this new species possible by loaning the holotype from the MLUH to the ZHMB. This allowed its thorough examination during the visit of M.A.C. to these collections. This name should be treated as a noun in the genitive case.

Type locality: Colombia. 
Geographical distribution. TRINIDAD AND TOBAGO (Scarborough), COLOMBIA, GUYANA, VENEZUELA (Anzoátegui, Bolívar, Guaricó, Sucre).

Remarks. Liogenys schneiderae Cherman, new species resembles L. quadridentata mainly in the body shape and size, color of the body and elytra, and in the quadridentate clypeus. However, L. schneiderae differs (L. quadridentata in parenthesis) in the clypeus being more rugose, with the impressions next to the frons more marked (not rugose); antenna with club shorter; anterior margin of pronotum slightly depressed throughout (not as so); elytral suture medially darker than the elytron (medially unicolored with elytron); metatibia flatter with inner margin abruptly subbasally produced towards apex (produced straight towards apex); ventrites I-IV with tubercles (without tubercles); and pygidium never inflated, with apex quadrate (pygidium convex in both sexes, inflated in females, pygidial apex rounded).

\section{Remarks on Central American Liogenys and new nomenclatural acts}

According to the morphological features, the Mexican species cited in Evans \& Smith (2009) belong to Diplotaxis instead of Liogenys (Vaurie 1958; Ramírez-Salinas \& Castro-Ramírez 2015; Cherman et al. 2016) and are hereby transferred to Diplotaxis: Diplotaxis puberea cuprascens (Bates, 1887) new combination; Diplotaxis puberea puberea (Bates, 1887) new combination; and Diplotaxis pubisternis (Bates, 1887) new combination. Moreover, D. puberea came up related to the other Diplotaxis species in Cherman et al. (2016).

With these relocations we here confirm that the distribution of Liogenys is strictly Neotropical, agreeing with Cherman et al. (2017) data. Taking into account the new species records presented here, the geographical distribution of Liogenys is updated from Trinidad and Tobago (St. George and Scarborough) towards South America, until southern Chile. Before this work, the northernmost country in Liogenys distribution was Panama (Cherman et al. 2017). Recently, Diplotaxis poropyge Bates, 1887, a species distributed from Mexico to the south of Panama (Vaurie 1958, 1960), was discovered in Colombia, and thus it is the first Diplotaxis recorded in South America (Mendoza \& García-Atencia 2019). According to Vaurie (1958), despite the overlapping distributions, these genera evolved independently; Diplotaxis in North America and Liogenys in South America. Nonetheless, there are no studies assessing the biogeographic history of these genera, or other Diplotaxini taxa.

\section{Acknowledgements}

We thank all of the curators and collection managers listed in the Material examined section who allowed us to visit their institutions, borrow specimens, and/or provided illustrations of specimens in their care. A special thanks to François Génier who took some of the photographs for us during the pandemic when we were unable to access our laboratories. We also thank anonymous reviewers for critically evaluating the manuscript and providing their valuable suggestions. We acknowledge the following research fundings: CNPq - Conselho Nacional de Desenvolvimento Científico e Tecnológico - MAC (151425/2019-1) and LMA (308992/2017-2); DAAD - German Academic Exchange Service of MAC (91703090), and CMNC Visiting Scientists Program (MAC-2018). This study was supported, in part, by a visiting scientist award to M.A.C. from the Beaty Centre for Species Discovery, Canadian Museum of Nature during the summer of 2018. This is the contribution number 1975 of Department of Zoology, Universidade Federal do Paraná.

\section{References cited}

Bates, H.W. (1887) Insecta. Coleoptera. Vol. II. Part 2. Pectinicornia and Lamellicornia. In: Salvin, O. \& Godman, F. du C. (Eds.), Biologia Centrali-Americana. R. H. Porter, London, pp. 25-160.

Blackwelder, R.E. (1944) Checklist of the Coleopterous Insects of Mexico, Central America, The West Indies and South America. Part 2. Smithsonian Institution, Washington, D.C., pp. 189-265.

https://doi.org/10.5479/si.03629236.185.2

Blanchard, É. (1851) Muséum d'Histoire Naturelle de Paris. Catalogue de la Collection Entomologique. Classe des Insectes. Ordre des Coléoptères. Tome I. Gide et Baudry, Paris, 240 pp.

Brookes, R. (1819) General Gazeteer...Illustrated with maps...The fifteenth edition...with considerable additions and 
improvements. $15^{\text {th }}$ Edition. Plummer and Brewis, Printers, Love-Lane, Little-Eastcheap, London, 796 pp.

Burmeister, H. (1855) Handbuch der Entomologie (Coleoptera Lamellicornia Phyllophaga chaenochela). Vierter Band. Zweite Abtheilung. Theod. Chr. Fr. Enslin, Berlin, 570 pp.

Cherman, M.A. \& Almeida, L.M. (2015) New Brazilian species of Liogenys Guérin-Méneville (Coleoptera: Melolonthidae: Melolonthinae) and redescription of two related species. Dugesiana, 22, 171-178.

Cherman, M.A., Basílio, D.S., Mise, K.M. \& Almeida, L.M. (2019) Unraveling the puzzle of Liogenys biodiversity: fifteen new species, nomenclatural acts and new geographical records (Coleoptera : Scarabaeidae ). Insect Systematics \& Evolution, $51,1-69$. https://doi.org/10.1163/1876312X-00001040

Cherman, M.A., Basílio, D.S., Mise, K.M., Frisch, J., Smith, A.B.T. \& Almeida, L.M. (2020) Liogenys Guérin-Méneville, 1831 (Coleoptera: Scarabaeidae: Melolonthinae) from the southern South American Transition Zone and boundaries: taxonomic overview with four new species. Zootaxa, 4896 (1), 46-84. https://doi.org/10.11646/zootaxa.4896.1.2

Cherman, M.A., Basílio, D.S., Mise, K.M., Frisch, J. \& Almeida, L.M. (2021) Liogenys Guérin-Méneville, 1831 (Coleoptera: Scarabaeidae: Melolonthinae: Diplotaxini) from the Chacoan Province and its boundaries: taxonomic overview with four new species. Zootaxa, 4938 (1), 1-59. https://doi.org/10.11646/zootaxa.4938.1.1

Cherman, M.A., Mise, K.M., Morón, M.A., Vaz-de-Mello, F.Z. \& Almeida, L.M. (2017) A taxonomic revision of Liogenys occurring in Brazil with an interactive key and remarks on New World Diplotaxini (Coleoptera, Melolonthidae). ZooKeys, $699,1-120$. https://doi.org/10.3897/zookeys.699.12031

Cherman, M.A., Morón, M.A. \& Almeida, L.M. (2016) Phylogenetic relationships within Diplotaxini Kirby (Coleoptera: Melolonthidae: Melolonthinae) with emphasis on Liogenys Guérin-Méneville. Systematic Entomology, 41, 744-770. https://doi.org/10.1111/syen.12188

Dalla Torre, K.W. von (1913) Scarabaeidae: Melolonthinae IV. Pars 50. In: Schenkling, S. (Ed.), Coleopterorum catalogus. Vol. $X X$. Junk, W., Berlin, pp. 291-450.

Delgado, L. \& Toledo-Hernández, V.H. (2020) Three new species of Diplotaxis Kirby from Guatemala and Mexico (Coleoptera, Scarabaeidae, Melolonthinae), with a key to the species of the trapezifera group. ZooKeys, 993, 35-46. https://doi. org/10.3897/zookeys.993.49434

Evans, A.V. (2003) A checklist of the NewWorld chafers (Coleoptera: Scarabaeidae: Melolonthinae). Zootaxa, 211 , 1-458. https://doi.org/10.11646/zootaxa.211.1.1

Evans, A.V. \& Smith, A.B.T. (2009) An electronic checklist of the New World chafers (Coleoptera: Scarabaeidae: Melolonthinae) version 3 2009. Papers in Entomology, 1, 1-344.

Evenhuis, N.L. (2020) The insect and spider collections of the world website. Available at: http://hbs.bishopmuseum.org/codens/ (accessed 6 August 2020)

Fabricius, J.C. (1798) Supplementum entomologiae systematicae. Proft et Storch, Copenhagen, 572 pp.

Frey, G. (1969) Bestimmungstabelle und revision der gattung Liogenys Guérrez (Coleoptera-Melolonthinae-Macrodactylini). Entomologische Arbeiten aus dem Museum G. Frey, 20, 38-64.

García-Atencia, S.P., Martínez-Hernández, N. \& Pardo-Locarno, L.C. (2015) Escarabajos fitófagos (Coleoptera: Scarabaeidae) en un fragmento de bosque seco tropical del departamento del Atlántico, Colombia. Revista Mexicana de Biodiversidad, $86,754-763$. https://doi.org/10.1016/j.rmb.2015.07.009

Grousset, F., Suffert, M. \& Petter, F. (2015) EPPO Study on pest risks associated with the import of tomato fruit. EPPO Bulletin, $45,153-156$. https://doi.org/10.1111/epp.12180

Harold, E.F. von (1869) Scarabaeidae. In: Gemminger, M. \& von Harold, E.F. (Eds.), Catalogus coleopterorum hucusque descriptorum synonymicus et systematicus. Vol. 4. E. H. Gummi, Munich, pp. 976-1346.

Lacordaire, M.T. (1855) Genera des Coléoptères. Famille XXX. Pectinicornes. In: Histoire Naturelle des Insectes. Librairie Encyclopedique de Roret, Paris, pp. 1-594.

Lawrence, J.F. (1999) The Australian Ommatidae (Coleoptera: Archostemata): new species, larva and discussion of relationships. Invertebrate Taxonomy, 13, 369-390. https://doi.org/10.1071/IT99008

Löwenberg-Neto, P. (2014) Neotropical region: a shapefile of Morrone's (2014) biogeographical regionalisation. Zootaxa, 3802 (2), 300-300. https://doi.org/10.11646/zootaxa.3802.2.12

Mendoza, I.A. \& García-Atencia, S.P. (2019) First record of the genus Diplotaxis Kirby, 1837 (Coleoptera, scarabaeidae, diplotaxini) in South America. Check List, 15, 435-439.

https://doi.org/10.15560/15.3.435

Morales-Valles, P., Cermeli, M., Godoy, F. \& Salas, B. (2003) Lista de insectos relacionados a las solanáceas ubicados en el Museo de Insectos de Interés Agrícola del CENIAP - INIA. Entomotropica, 18, 193-209.

Morrone, J.J. (2014) Biogeographical regionalisation of the Neotropical region. Zootaxa, 3782 (1), 1-110. 
https://doi.org/10.11646/zootaxa.3782.1.1

Moser, J. (1921) Neue Melolonthiden von Mittel- und Süd-Amerika. Stettiner Entomologische Zeitung, 82, 133-182. https://doi.org/10.1002/mmnd.192119210312

Nonfried, A.F. (1892) Verzeichniss der seit 1871 neu beschriebenen Glaphyriden, Melolonthiden und Euchiriden. Berliner Entomologische Zeitschrift, 37, 249-290. https://doi.org/10.1002/mmnd.18920370302

Ramírez-Salinas, C. \& Castro-Ramírez, A.E. (2015) Descripción del tercer estadio larval de Ceraspis pilatei (Harold, 1863), Diplotaxis puberea (Bates, 1887) y Phyllophaga (s.str.) multipora (Bates, 1888) (Coleoptera: Melolonthidae) de Chiapas, México. Dugesiana, 22, 251-259.

Ratcliffe, B.C. (2013) Best writing and curatorial practices for describing a new species of beetle: a primer. The Coleopterists Bulletin, 67, 107-113. https://doi.org/10.1649/0010-065X-67.2.107

United States Department of Agriculture [USDA] (1969) List of intercepted plant pests, 1968 (Pest recorded from July 1, 1967, through June 30, 1968). Hayattsville, Maryland. U.S. G.P.O., Washington, D.C., pp. 46-58.

United States Department of Agriculture [USDA] (1971) Insects not known to occur in the United States: A Scarab (Liogenys macropelma Bates). Cooperative Economic Insect Report, 21, 335-336.

United States Department of Agriculture [USDA] (1974) List of intercepted plant pests, 1972 (Pest recorded from July 1, 1971, through June 30, 1972). Hayattsville, Maryland. U.S. G.P.O., Washington, D.C., pp. 55-68.

Vaurie, P. (1958) A revision of the genus Diplotaxis (Coleoptera, Scarabaeidae, Melolonthinae). Part 1. Bulletin of the American Museum of Natural History, 115, 269-396.

Vaurie, P. (1960) A revision of the genus Diplotaxis (Coleoptera, Scarabaeidae, Melolonthinae) Part 2. Bulletin of the American Museum of Natural History, 120, 161-434. https://doi.org/10.5962/bhl.part.4716

\section{Additional information}

Article in press: <http://zoobank.org/DB19CD93-CCCD-4A3F-A80E-74114513BDAC>

http://zoobank.org/urn:lsid:zoobank.org:pub:2C8C9945-A40A-409F-AD90-DE6A792285B3

*Liogenys clipeosetosa *Cherman in Cherman, Basilio, Mise, Frisch, Smith \&

Almeida, In Press: http://zoobank.org/6299F159-66BD-4725-BB57-F8ACBFDB5DF4

*Liogenys genieri *Smith \& Cherman in Cherman, Basilio, Mise, Frisch, Smith

\& Almeida, In Press: <http://zoobank.org/0D51DD77-5048-4285-B0F6-A0785885A6F0>

http://zoobank.org/828B2892-0A98-453E-8AA0-0EB3B98DDBD3

*Liogenys granadina *Cherman in Cherman, Basilio, Mise, Frisch, Smith \& Almeida, In Press: http://zoobank.org/A7B78055-B846-4306-9474-2378F0E9E460

<http://zoobank.org/A7B78055-B846-4306-9474-2378F0E9E460>

*Liogenys schneiderae *Cherman in Cherman, Basilio, Mise, Frisch, Smith \& Almeida, In Press:

http://zoobank.org/F2604CEF-CE49-4733-9840-2F5D8CA84437 